\title{
Energy assessment of different cooling technologies in Ti-6Al-4V milling
}

\author{
Paolo Albertelli ${ }^{1,2}$ (D) Michele Monno ${ }^{1,2}$ (D) \\ Received: 28 August 2020 / Accepted: 28 December 2020 / Published online: 15 January 2021 \\ (C) The Author(s) 2021
}

\begin{abstract}
Manufacturing craves for more sustainable solutions for machining heat-resistant alloys. In this paper, an assessment of different cooling lubrication approaches for Ti6Al4V milling was carried out. Cryogenic cutting (liquid nitrogen) and conventional cooling (oil-based fluid) were assessed with respect to dry cutting. To study the effects of the main relevant process parameters, proper energy models were developed, validated and then used for comparing the analysed cooling lubrication strategies. The model parameters were identified exploiting data from specifically conceived experiments. The power assessment was carried out considering different perspectives, with a bottom-up approach. Indeed, it was found that cryogenic cooling, thanks to a better tribological behaviour, is less energy demanding (at least 25\%) than dry and conventional cutting. If the spindle power is considered, lower saving percentages can be expected. Cryogenic cooling showed its best energy performance (from 3 to 11 times) with respect to conventional cutting if the machine tool perspective is analysed. Considering even the primary energy required for producing the cutting fluids, the assessment showed that cryogenic cooling requires up to 19 times the energy required for conventional cutting.
\end{abstract}

Keywords Sustainability $\cdot$ Ti6Al4V milling $\cdot$ Energy $\cdot$ Cryogenic $\cdot$ Lubricant $\cdot$ Dry cutting

\section{Introduction}

Although titanium components are widely adopted in many high-performance applications, ranging from biomechanical to aerospace, its machinability is still a stimulating challenge both for manufacturing industries and for the research community [1]. Due to high chemical reactivity, low thermal conductivity and high material strength that is preserved at high temperatures, titanium and other heat-resistant alloys HRA are considered hard-to-cut materials. They can only be unprofitably processed [2] at low cutting speeds with the auxiliary of metalworking fluids (MWFs) [3]. Water miscible and oil-based cutting fluids (namely, conventional cooling) are the most widely diffused solutions for processing HRA in shop-floors. It was

Paolo Albertelli

paolo.albertelli@polimi.it

1 Mechanical Engineering Department, Politecnico di Milano, Via La Masa 1, 20156 Milan, Italy

2 Laboratorio MUSP., strada Torre della Razza, 29122 Piacenza, Italy estimated that the costs associated to cutting fluids account for the $25 \%$ of the overall manufacturing costs [4].

Although productivity and machining costs are still the main drivers in machining technology development, in recent years, environmental sustainability [5] and health issues [6, 7] have been gaining an increasing attention. Adler et al. [8] analysed the main limitations of the existing cooling lubricating CL methodologies.

Several recent review papers focused on sustainability in machining [9, 10]. Gupta and Laubscher [11] give an overview of the most promising and advanced CL methods from pursuing the sustainability. The use of cryogenic fluids and minimum quantity lubrication MQL and the combination of MQL and cryogenic are subject of many research efforts. As summarized in Table 1, several aspects have been investigated, from the system development to the assessment of the different CL methodologies where different approaches were used. Most of the studies adopted experimental methods, some works combine numerical and experimental methods, while few works exploited already published data to perform comparative analyses.

Pervaiz et al. [12] resume the recent advances in MQL titanium machining. It was demonstrated that the cooling 
Table 1 Sustainable machining - literature review map

\begin{tabular}{|c|c|c|c|c|c|}
\hline & & Cryo-LN & Cryo-CO2 & MQL & Cryo-MQL \\
\hline & Modelling/validation & {$[48](\mathrm{T}, \mathrm{tb}, \mathrm{m} 1, \mathrm{c} 0)$} & {$[49](\mathrm{M}, \mathrm{tb}, \mathrm{th}, \mathrm{c} 3)$} & & \\
\hline & & {$[46](\mathrm{T}, \mathrm{tb}, \mathrm{m} 1, \mathrm{c} 6)$} & & & \\
\hline & & {$[45](\mathrm{M}, \mathrm{tb}, \mathrm{m} 1, \mathrm{c} 6)$} & & & \\
\hline & & {$[62](\mathrm{T}, \mathrm{tb}, \mathrm{m} 1, \mathrm{c} 6)$} & & & \\
\hline & System development & {$[39](\mathrm{O}, \mathrm{dm}, \mathrm{ml}, \mathrm{c5})$} & & & {$[17](\mathrm{M}, \mathrm{nb}, \mathrm{tw}, \mathrm{c5})$} \\
\hline & & {$[44](\mathrm{M}, \mathrm{dm}, \mathrm{th}, \mathrm{c} 0)$} & & & {$[18](\mathrm{M}, \mathrm{dm}, \mathrm{m} 1, \mathrm{c} 5)$} \\
\hline & & & & & [19](M,nb,tw,c5) \\
\hline & & & & & {$[20](\mathrm{M}, \mathrm{tb}, \mathrm{tw}, \mathrm{c} 1)$} \\
\hline & & & & & {$[21](\mathrm{M}, \mathrm{tb}, \mathrm{tw}, \mathrm{c} 1)$} \\
\hline & Process optimization & [41] (T,nb,m1,c5) & & & \\
\hline & & [53] $(\mathrm{T}, \mathrm{nb}, \mathrm{m} 1, \mathrm{c} 5)$ & & & \\
\hline \multirow{26}{*}{$\begin{array}{l}\text { Assessment and } \\
\text { corresponding adopted } \\
\text { methodology }\end{array}$} & Experimental & {$[43](\mathrm{M}, \mathrm{tb}, \mathrm{th}, \mathrm{c} 5)$} & {$[40](\mathrm{T}, \mathrm{st}, \mathrm{m} 1, \mathrm{co} 0)$} & {$[13](T, t b, e n, c 1)$} & {$[22](\mathrm{O}, \mathrm{st}, \mathrm{m} 1, \mathrm{c} 1)$} \\
\hline & & {$[57](\mathrm{M}, \mathrm{tb}, \mathrm{m} 1, \mathrm{c} 5)$} & {$[56](\mathrm{M}, \mathrm{tb}, \mathrm{m} 1, \mathrm{c} 1)$} & & {$[23](\mathrm{T}, \mathrm{st}, \mathrm{m} 2, \mathrm{c} 5)$} \\
\hline & & {$[58](\mathrm{T}, \mathrm{tb}, \mathrm{m} 2, \mathrm{c} 0)$} & {$[50](\mathrm{M}, \mathrm{tb}, \mathrm{tw}, \mathrm{c} 1)$} & & {$[24](\mathrm{M}, \mathrm{nb}, \mathrm{m} 1, \mathrm{c} 5)$} \\
\hline & & {$[38](\mathrm{T}, \mathrm{nb}, \mathrm{m} 2, \mathrm{c} 1)$} & {$[52](\mathrm{T}, \mathrm{st}, \mathrm{m} 1, \mathrm{c} 5)$} & & {$[25](\mathrm{M}, \mathrm{nb}, \mathrm{ml}, \mathrm{c} 5)$} \\
\hline & & {$[10](\mathrm{T}, \mathrm{tb}, \mathrm{m} 2, \mathrm{c} 5)$} & {$[42](\mathrm{O}, \mathrm{tb}, \mathrm{m} 2, \mathrm{c} 5)$} & & {$[27](\mathrm{T}, \mathrm{dm}, \mathrm{tw}, \mathrm{c} 5)$} \\
\hline & & {$[60](\mathrm{M}, \mathrm{tb}, \mathrm{m} 2, \mathrm{c} 5)$} & {$[51](\mathrm{M}, \mathrm{tb}, \mathrm{tw}, \mathrm{c} 1)$} & & {$[28](\mathrm{M}, \mathrm{tb}, \mathrm{tw}, \mathrm{c} 5)$} \\
\hline & & {$[63](\mathrm{T}, \mathrm{tb}, \mathrm{m} 1, \mathrm{c} 1)$} & & & {$[29](\mathrm{T}, \mathrm{tb}, \mathrm{m} 1, \mathrm{c} 5)$} \\
\hline & & {$[64](\mathrm{T}, \mathrm{tb}, \mathrm{f}, \mathrm{c} 1)$} & & & {$[26](\mathrm{M}, \mathrm{tb}, \mathrm{tw}, \mathrm{c} 5)$} \\
\hline & & {$[65](\mathrm{T}, \mathrm{tb}, \mathrm{m} 1, \mathrm{c} 6)$} & & & {$[30](\mathrm{T}, \mathrm{dm}, \mathrm{m} 1, \mathrm{c} 1)$} \\
\hline & & {$[66](\mathrm{T}, \mathrm{tb}, \mathrm{tw}, \mathrm{c} 1)$} & & & {$[31](\mathrm{O}, \mathrm{dm}, \mathrm{m} 1, \mathrm{c} 1)$} \\
\hline & & {$[67](\mathrm{T}, \mathrm{tb}, \mathrm{m} 1, \mathrm{c} 6)$} & & & \\
\hline & & {$[68](\mathrm{T}, \mathrm{tb}, \mathrm{m} 1, \mathrm{c} 6)$} & & & \\
\hline & & {$[69](O, s t, e n, c 5)$} & & & \\
\hline & & {$[70](\mathrm{T}, \mathrm{tb}, \mathrm{m} 1, \mathrm{c} 1)$} & & & \\
\hline & & {$[36](\mathrm{T}, \mathrm{tb}, \mathrm{m} 1, \mathrm{c} 1)$} & & & \\
\hline & & {$[37](\mathrm{M}, \mathrm{tb}, \mathrm{m} 1, \mathrm{c} 5)$} & & & \\
\hline & & {$[55](\mathrm{T}, \mathrm{tb}, \mathrm{m} 1, \mathrm{c} 5)$} & & & \\
\hline & & {$[54](\mathrm{T}, \mathrm{tb}, \mathrm{m} 1, \mathrm{c} 6)$} & & & \\
\hline & & {$[47](\mathrm{T}, \mathrm{st}, \mathrm{m} 1, \mathrm{c} 6)$} & & & \\
\hline & Validated model & $\begin{array}{l}\text { [present } \\
\text { wok](M,tb,en,C5) }\end{array}$ & & & \\
\hline & Numerical-experimental & {$[59](T, t b, e n, c 5)$} & & {$[16](\mathrm{T}, \mathrm{tb}, \mathrm{m} 2, \mathrm{c} 0)$} & \\
\hline & & {$[71](\mathrm{T}, \mathrm{st}, \mathrm{m} 1, \mathrm{c} 6)$} & & {$[14](\mathrm{T}, \mathrm{nb}, \mathrm{m} 2, \mathrm{c} 0)$} & \\
\hline & & {$[72](T$, tb,th,c6) } & & {$[15](\mathrm{T}, \mathrm{st}, \mathrm{m} 2, \mathrm{c} 0)$} & \\
\hline & State of art review & {$[9](\mathrm{O}, \mathrm{dm}, \mathrm{en}, \mathrm{c} 5)$} & {$[61](\mathrm{O}, \mathrm{dm}, \mathrm{m} 2, \mathrm{c} 5)$} & & \\
\hline & & {$[35](\mathrm{O}, \mathrm{dm}, \mathrm{m} 2, \mathrm{c} 5)$} & & & \\
\hline & & {$[61](\mathrm{O}, \mathrm{dm}, \mathrm{m} 2, \mathrm{c} 5)$} & & & \\
\hline
\end{tabular}

[Reference number] (Application, material, performance index, comparison). Application: $M$ milling, $T$ turning, $O$ other machining operations or different machining operation. Material: $t b$ titanium-based alloys, $n b$ nickel-based alloys, $s t$ steel, $d m$ different materials or other materials. Performance index: $t w$ tool wear, $w q$ workpiece quality (i.e. roughness), th thermal behaviour, lca life cycle assessment, en energy, $m 1$ miscellaneous (process-product related performance i.e. tool wear, surface quality and residual stress analysis), $m 2$ miscellaneous (combination of process-product related indexes and environment-related aspects). Comparison to: $c 0$ no comparison, $c 1$ conventional CL, $c 2$ cryo, $c 3 \mathrm{MQL}, c 4$ cryo $+\mathrm{MQL}, c 5$ multiple comparisons, $c 6$ dry

action of the oil is rather limited since the involved flow rates are very low $(10-150 \mathrm{ml} / \mathrm{h})$. The reduction of friction is the most relevant observed effect of MQL. Improvements in terms of surface integrity and tool life were observed even if in most of the studies the assessments were carried out with respect to dry cutting. In [13], an experimental assessment of surface roughness, chip morphology and energy consumption with respect to wet machining was carried out. Khan et al. in $[14,15]$ proposed an empirical model for studying the effect of the main parameters on the costs and overall energy demand. A comprehensive analysis considering process- and product-related performances (tool wear, productivity, surface roughness, etc.) and specific energy was carried out in [16].

In order to enhance the cooling potentialities of MQL, the development of a hybrid CL method that combines a cryogenic fluid with MQL (cryo-MQL) was carried out in many studies. Pereira et al. [17-19] designed specific nozzles for cryoMQL. Computer fluid dynamics (CFD) simulations were performed to optimize the system performances. A preliminary assessment (tool life) with respect to other CL technologies was performed. It was found that the hybrid cryo-MQL showed lower performance than conventional cutting. 
Grguraš et al. [20] developed a solution for feeding the mixed LCO2-oil flow through the inner mill nozzles. Bergs et al. [21] studied the solubility of different oils in $\mathrm{LCO} 2$ jets. For this purpose, a specific mixing chamber was designed.

Several works carried out comparative analysis considering cryo-MQL and other CL methods. For instance, Superkar et al. [22] demonstrated the efficacy of supercritical CO2MWFs jets in turning, drilling and tapping. Pereira et al. in $[23]$ and $[24,25]$ respectively performed turning tests on steel and milling experiments on Inconel 718. Although remarkable results in terms of tool life and surface quality enhancement were observed, milling tests revealed that conventional cooling still assures the best performances. Similar results were observed by Tapoglou in [26]. In Bagherzadeh et al. [27] it was found that an optimized cryogenic ( $\mathrm{CO} 2)$ cooling is still more effective than cryo-MQL.

Shokrani et al. [28] performed milling tests on Ti6Al4V using an experimental set-up composed of four external nozzles for feeding, separately, both the C02 and the MQL jets on the tool. Maybe due to a non-optimized design, the observed tool life was comparable to the results achieved with MQL, especially at high cutting speed. Damir et al. [29] found that hybrid cryo-MQL assured tool life durations comparable to the ones achieved using high-pressure coolant HPC turning. Similar results were found by Gross et al. [30] in turning. Hanenkamp et al. [31] discovered that the mill duration (cryo + MQL) was strongly affected by the oil properties.

According to [32-35], the expected advantages of cryogenic machining are related to the potential increment of material removal rates (MRR), the extension of the tool life and the enhancement of the quality/integrity of processed surfaces $[36,37]$, and it prevents the oil contamination of the parts, chips and machine. Pusavec et al. in [38] tried to formalize all these aspects to compare different CL solutions. They proposed an overall cost function that considers even the contributions for cleaning the parts and the swarf, the cost for the MWFs disposal, the machine cost and the cost of energy. Although the results confirmed the great potentialities of cryogenic cooling, some difficulties need to be tackled.

For instance, the storage and delivery of LN2 is problematic. Indeed, a proper vacuum-insulated vessel and feeding system are necessary. The insulation of the most critical machine tool components (i.e. spindle bearings) and the need to prevent any early LN2 gasification are demanding challenges. Even a proper integration of the cryogenic solutions in real machine centres and shop-floors is tough. Paul in [39] analysed these aspects and presented some feasible solutions. On the contrary, $\mathrm{CO} 2$ can be more easily stored at ambient temperature but adopting higher pressures. $\mathrm{CO} 2$ is relatively cheap and for this reason is more attractive industrially than other cryogenic gases [40]. The drawbacks of cryogenic CO2 are related to a slightly irritating odour and higher density than air, and this can cause serious problems to workers unless proper air exchange is assured. For what concerns the cooling performance, it was estimated that LN2 assures a $20 \%$ higher refrigeration value than $\mathrm{CO} 2$ [41]. Moreover, when liquid $\mathrm{CO} 2$ sprayed through the nozzle, due to a high-pressure drop the liquid, $\mathrm{CO} 2$ changes phase into a mixture of a solid (dry ice) and gaseous state, thus reducing its cooling properties. This was confirmed by Shah et al. in [42]. The authors compared cryogenic $\mathrm{CO} 2$ and LN2 in titanium alloy drilling. It was found that LN2 made the drill life $45 \%$ longer than $\mathrm{CO} 2$. Conflicting results were reported in [43] since the results strongly depend on the cryogenic jet properties (i.e. position, orientation).

In some works, the development of a proper system [44] for feeding the cryogenic fluid was carried out even with the support of advanced simulations [45-47]. Shi et al. [48] developed a hybrid numerical approach that used CFD simulation results for properly setting the corresponding FE model. Augspurger et al. [49] combined an analytical formulation and temperature measurements for evaluating the cooling performance of $\mathrm{CO} 2$ in titanium milling.

Sadik et al. [50] performed wear tests in Ti6Al4V milling adopting cryogenic $(\mathrm{C} 02)$ and conventional cutting. It was observed that cryogenic cutting assured higher tool life even changing the orifice size. Similar results were achieved in [51]. Khanna et al. [52] extended the analysis performing tests on precipitation hardening ( $\mathrm{PH}$ ) stainless steel (SS) adopting cryogenic $\mathrm{CO} 2$ and other $\mathrm{CL}$ methods. Even the reduction of the power consumption was observed in cryogenic condition.

Pusavec et al. in [41] carried out an experimental study on the main sustainable CL techniques for machining Inconel 718. They developed an empirical model using the response surface methodology RSM. In [53] an optimization process considering even the chip breakability was carried out.

Bordin et al. [54, 55] carried out comparative turning tests on Ti6Al4V produced by additive manufacturing. Cryogenic LN2 showed the better performance in terms of tool life with respect to conventional turning. Isakson et al. [56] compared cryogenic LN2 and conventional Ti6Al4V turning analysing the wear of the tool, the residual stresses and the surface roughness. It was found that wet turning assured a higher tool life.

Suhaimi et al. [57] experimented different LN2-assisted solutions for Ti6Al4V milling. It was found that in cryogenic milling, higher tool life occurred especially if with the developed indirect cooling strategy. Damir et al. [58] performed comparative turning tests adopting both LN2 and conventional cooling. With the auxiliary of LN, lower forces and a better surface finishing were observed. Moreover, it was demonstrated that with the adoption of LN2, a lower total single score, in terms of overall consumed energy, can be achieved.

Gupta et al. [59] proposed a study for comparing cryogenic (LN2) cutting turning with wet turning. In surface finishing, temperature add roughness were evaluated. Moreover, energy 
consumption and carbon emission were evaluated. The lowest energy consumption was observed for the combination LN2MQL even if similar results were obtained just using LN2. Shokrani et al. [60] compared cryogenic milling with respect to conventional cooling. The authors used an experimental approach to assess the absorbed power with different machining parameters. They found that cryogenic cutting is more energy demanding, focusing on the energy absorbed by the machine, than dry cutting but less energy demanding than conventional cutting. Moreover, although the cutting tests were executed changing the parameters, only the average power was considered in the assessment.

According to the scientific literature (Table 1), most of the studies were focused on the process-product-related performances, while few research works really dealt with the environmental issues. Pusavec et al. in [35] stated that cryogenic machining is the sole cooling technology that has a disruptive effect on the indicators that are typically used for assessing the life cycle (LCA) of a process (CO2, water use, acidification, energy, solid waste, etc.). From this perspective, only dry cutting has similar environmental-oriented capabilities, but, according to the present tooling technology, it cannot be considered an industrial and profitable solution for processing hard-to-cut materials. Some of the already analysed papers (i.e. [59, 60]) experimentally observed an energy consumption reduction associated to the use of cryogenic in machining even if the analyses were typically carried out in specific cutting conditions. If the system boundaries were enlarged to the LN2 production, Pusavec et al. in [35] found that the energy demand in cryogenic machining is higher than in other $\mathrm{CL}$ methods since the LN2 liquefaction process is energy demanding. A different conclusion was outlined by Damir et al. in [58]. Another study on the overall energy request was carried out in [61]. It compared both conventional cutting and cryogenic cooling exploiting data from other research works. Since some data were missing, a specific procedure to assume them or to compare different scenarios, characterized by different processed materials, experimental set-ups, feeding systems, process parameters and machining operations, was adopted. Although the results were statistically analysed, they seem affected by the adopted procedure. In this research, it was found that $\mathrm{CO} 2$ is better than LN2 (averagely), but in many cases, much higher energy demands were observed.

In order to overcome the limitations described in the analysed research works, in this paper, a more structured approach was proposed for comparing cryogenic (LN2), conventional ad dry cutting. The assessment was performed at different levels adopting a bottom-up approach. The analysis started focusing on the tribological aspects involved in the cutting and then was extended up to the primary level where even the energy required to produce the cutting fluids was considered. For each perspective, a model was developed to analysed the effect of cutting parameters and other relevant process-related quantities. The models were properly characterized and validated through experiments. For this purpose, a reliable cryogenic set-up (developed in [45]) was exploited.

The proposed approach, together with the development of each sub-system model and the associated parameters identification procedure, was described in section "Materials and methods." Moreover, a detailed description of both the experimental set-up and the performed tests was also provided. In the "Results and discussion" section, the main results and the sensitive analyses were reported and commented. Conclusions were also outlined.

\section{Materials and methods}

In this section, the procedure devised for carrying out the energy assessment of cryogenic milling and conventional cooling with respect to dry cutting was presented. Although dry cutting is far from being profitably used in titanium milling, it represents the reference from the environmental perspective. As schematized in Fig. 1, the analysis was performed at different levels. At the bottom one, the cutting power was considered. In addition, considerations about the effects of the cooling lubrication approach on cutting forces and on the tribological behaviour were outlined. The achieved results were compared to the results found in literature [62-64]. At the second level, the analysis was carried out considering the spindle system boundaries, while the machine boundaries were considered for the third assessment. Finally, at the top level, the primary global energy (cumulative energy demand (CED)) required for producing the cutting fluids was also considered in the analysis.

At each level, for being able to study the effects of the main process-related parameters, an energy model was developed. Contextually, experimental test results (cutting force measurements and power measurements in different conditions) together with identification procedures were used to estimate the unknown model parameters. Proper tests were also carried out for model validation purposes.

A 4-axes machine centre was used for the experimentation. Since the results achieved in most of the papers that deal with cryogenic machining strongly depend on the specific adopted experimental set-up, an advanced through-tool cryogenic system [45] was used in this research. Although supplying a constant cryogenic coolant flow of liquid nitrogen LN2 through the inner channels of a rotating tool in a complex machine is a technological challenge since any small heat transfer or pressure drops inside the coolant feeding system [45] can evaporate a portion of the liquid with a combination of boiling and cavitation effects, this solution guaranties better cooling performance $[65,66,73]$ with respect to flood cryogenic cooling both in terms of expected cutting performance 


\section{ENERGY ASSESSMENT OF COOLING-LUBRICATING TECHNOLOGIES}

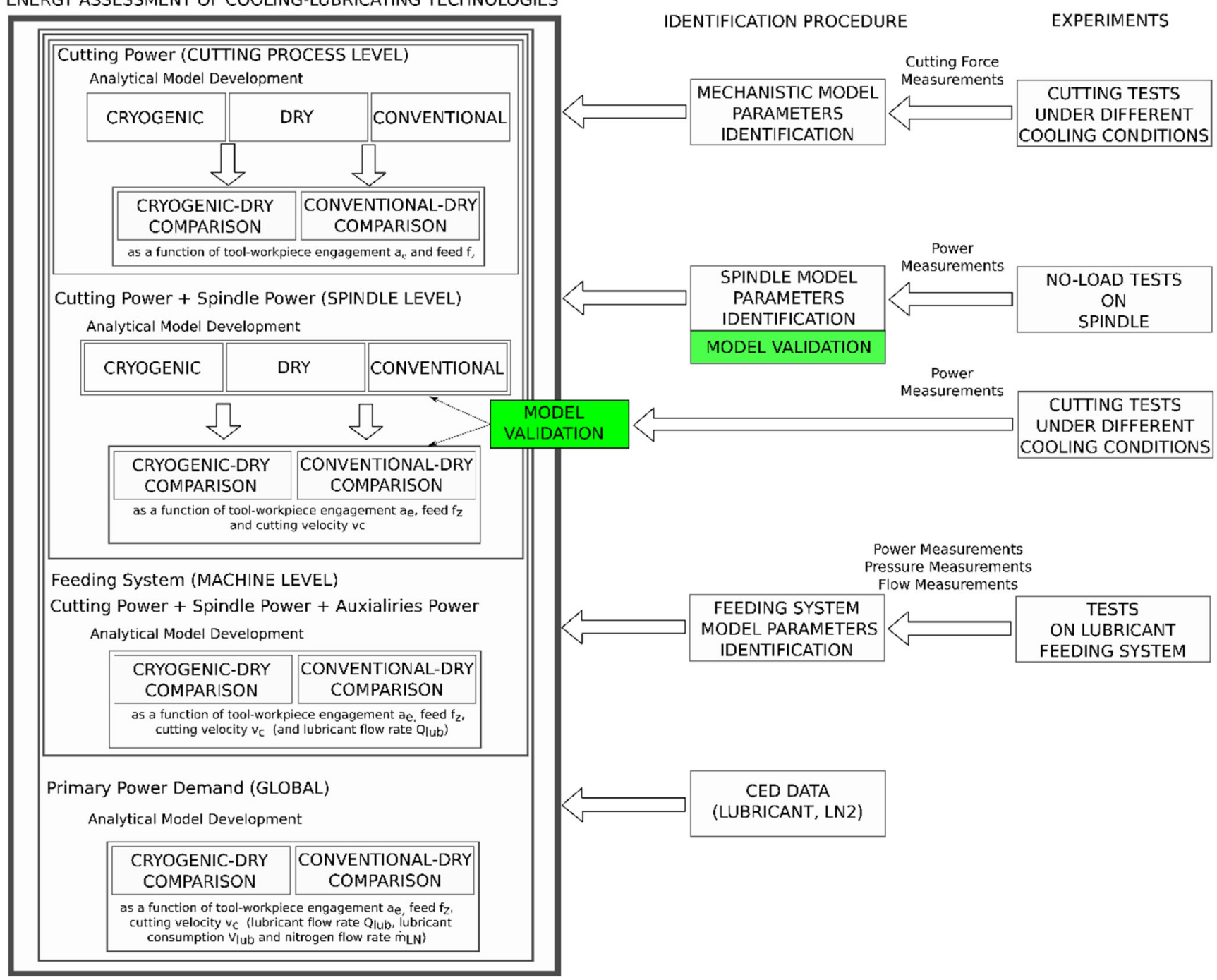

Fig. 1 The proposed approach for assessing the power of different cooling strategies in Ti6A14V milling at different levels

(i.e. $[63,67])$ and liquid nitrogen consumption. More details on the experimental set-up were reported in the following subsections.

\subsection{Cutting power assessment}

To accomplish the goal of this research, suitable models were properly developed. For the cutting process perspective, it was decided to start from one of the cutting force mechanistic models available in literature. More specifically, according to the representation of a generic peripherical milling operation reported in Fig. 2, the selected mechanistic model is described by Eqs. 1, 2, 3 and 4. This formulation is typically used for dealing with vibrational issues in machining [74]. As can be observed, the resulting cutting force on the engaged $i^{\text {th }}$ insert/tooth can be projected along the radial direction $F_{\text {ri }}$, the tangential direction $F_{\mathrm{ti}}$ and the axial direction $F_{\mathrm{ai}}$.
The force contributions on each insert can be computed according to Eq. 1.

$$
\begin{aligned}
& F_{t i}\left(\varphi_{i}(t)\right)=K_{t c} \cdot a_{p} \cdot h_{i}\left(\varphi_{i}(t)\right)+K_{t e} \cdot a_{p} \\
& F_{r i}\left(\varphi_{i}(t)\right)=K_{r c} \cdot a_{p} \cdot h_{i}\left(\varphi_{i}(t)\right)+K_{r e} \cdot a_{p} \\
& F_{a i}\left(\varphi_{i}(t)\right)=K_{a c} \cdot a_{p} \cdot h_{i}\left(\varphi_{i}(t)\right)+K_{a e} \cdot a_{p}
\end{aligned}
$$

$K_{t c}, K_{t e}, K_{r c}, K_{t e}, K_{a c}, K_{a e}$ are the coefficients of the mechanistic model, $a_{p}$ is the axial depth of cut and $h_{i}$ the instantaneous chip thickness that varies according to the angular coordinates $\varphi_{i}$, Eqs. 2 and 4.

$h_{i}\left(\varphi_{i}(t)\right)=f_{z} \cdot \sin \left(\varphi_{i}(t)\right)$

$\omega$ is the angular tool velocity assumed constant over time $t$, $a_{e}$ is the radial depth of cut and $f_{z}$ is the feed per tooth. These are the parameters typically set by the user before cutting. This mechanistic force model was selected because it considers, for the computation of the main cutting force components, a 


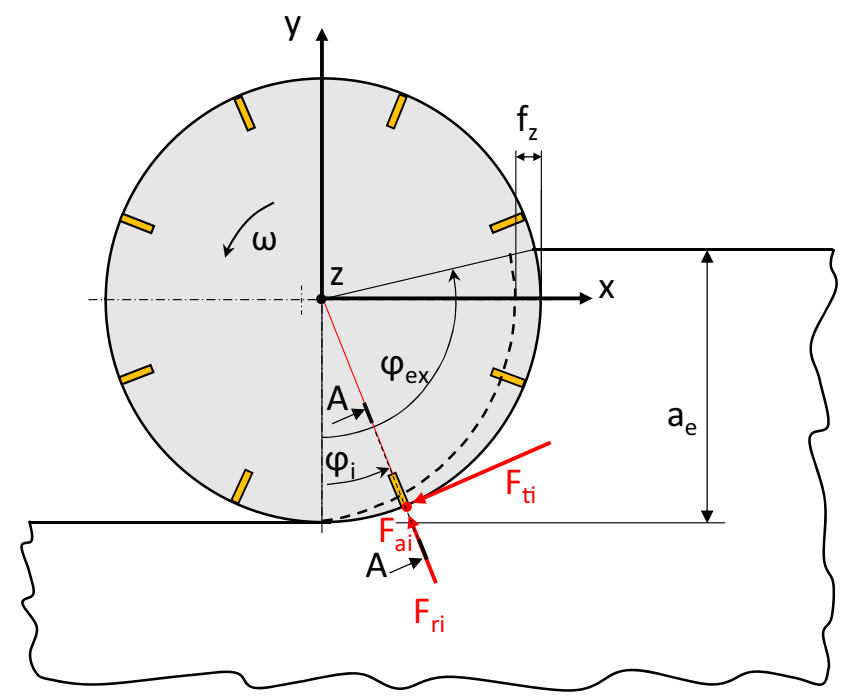

tooth/insert A-A

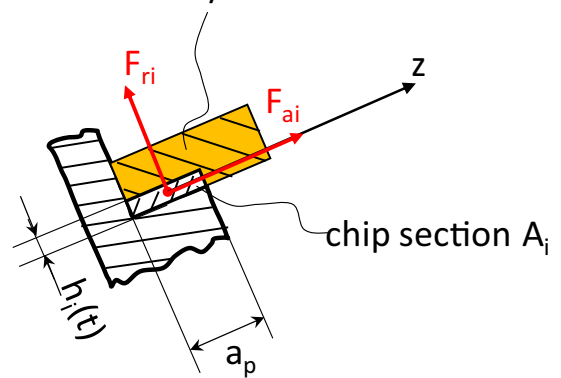

Fig. 2 Milling process and representation of the cutting forces acting on a generic insert

contribution due to the shear (proportional to the chip section $A_{i}$ ) and one linked to the friction/ploughing mechanism that, in this formulation, is considered proportional to the length of the cutting edge involved in the cutting.

$A_{i}\left(\varphi_{i}(t)\right)=h_{i}\left(\varphi_{i}(t)\right) \cdot a_{p}$

$\varphi_{i}(t)=\omega \cdot t$

Since $f_{z}$ is typically much lower that $a_{p}$, the length of the insert can be approximated with $a_{p}$. The formulation does not consider the tool radius.

$A_{i}\left(\varphi_{i}(t)\right)=f_{z} \cdot \sin \left(\varphi_{i}(t)\right) \cdot a_{p}$

Such a simple model has the desired features for the purposes of this research since it considers the main mechanisms responsible for the force generation, and it was expected that the CL strategy affects them together with the resulting cutting power.

Indeed, the instantaneous cutting power associated to each insert $P_{\text {cut }}(t)$ can be estimated through Eq. 6 .

$P_{c u t i}(t)=F_{t i}(t) \cdot v_{c}=K_{t c} \cdot a_{p} \cdot h_{i}\left(\varphi_{i}(t)\right) \cdot v_{c}+K_{t e} \cdot a_{p} \cdot v_{c}(6)$

According to Eq. 7, the average cutting power can be estimated considering a period of time $T$ associated to one revolution of the tool and the corresponding number of teeth $Z$. D is the tool diameter.

$\bar{P}_{c u t}=\frac{1}{T} \int_{0}^{T} Z \cdot F_{t i}(t) \cdot v_{c} \cdot d t$

$T$ can be computed knowing the cutting speed and the spindle speed rotation $\Omega$ (Eq. 8):
$T=\frac{\pi D}{v_{c}}=\frac{2 \pi}{\omega} ; \omega\left[\frac{\mathrm{rad}}{s}\right]=\frac{2 \pi \Omega[\mathrm{rev} / \mathrm{min}]}{60}$

Substituting Eq. 6 in Eq. 7 and considering that the cutting force is not null only when the tooth is engaged in the workpiece, that is when the associated angular $\varphi_{i}$ is in between $\varphi_{s t}$ and $\varphi_{e x}$ (respectively the starting and exit immersion angle, Fig. 2), Eq. 9 can be written.

$\bar{P}_{c u t}=\frac{1}{T} \int_{0}^{T} Z \cdot\left(K_{t c} \cdot a_{p} \cdot f_{z} \cdot \sin \left(\varphi_{i}(t)\right)+K_{t e} \cdot a_{p}\right) \cdot v_{c} \cdot d t$

The relationships can therefore be simplified as follows:

$\bar{P}_{c u t}=\frac{1}{T} \int_{0}^{\frac{\varphi_{e x}}{\omega}} Z \cdot\left(K_{t c} \cdot a_{p} \cdot f_{z} \cdot \sin (\omega \cdot t)+K_{t e} \cdot a_{p}\right) \cdot v_{c} \cdot d t$

Integrating the previous formulation, the average cutting power $\bar{P}_{c u t}$ can be expressed as reported in Eq. 11 .

$\bar{P}_{c u t}=Z \cdot K_{t c} \cdot a_{p} \cdot f_{z} \cdot\left(\frac{a_{e}}{\pi \cdot D}\right) \cdot v_{c}+Z \cdot K_{t e} \cdot a_{p} \cdot \frac{\varphi_{e x}}{2 \pi} \cdot v_{c}$

The relationship considers the non-dimensional ratio $a_{e} /(D)$ and the $\varphi_{e x} /(2 \pi)$ that both give and indicate the radial toolworkpiece engagement. Moreover, the dependence upon the feed $f_{z}$ is also visible.

Finally, the cutting power comparison linked to each specific cooling lubricating condition $\Delta P_{\text {cutt }_{j-d r y}}$ can be formalized as reported in Eq. 12. $\bar{P}_{\text {cutt }_{j}}$ is the average cutting power linked to the specific cooling strategy (cryogenic or conventional cooling). The $\Delta P_{\text {cutt }_{j-d r y}}$ was normalized, for both the conventional-dry and cryogenic-dry comparisons, with respect to the cutting power in dry cutting $\bar{P}_{c u t t_{d y}}$. 
$\Delta P_{\text {cutt }_{j-d y}}[\%]=100 \cdot \frac{\overline{\Delta P}_{\text {cutt }_{j-d y}}}{\bar{P}_{\text {cutt dry }}}=100 \cdot \frac{\left(\bar{P}_{\text {cut }_{j}}-\bar{P}_{\text {cut }_{d y}}\right)}{\bar{P}_{\text {cut }_{d r y}}}$

According to Eq. 12, it is worth noting that $\Delta P_{\text {cutt }_{j-d r y}}$ is twofold. Indeed, at the numerator, the first term is proportional to the difference of the tangential cutting coefficients, while the second depends on the difference of the edge tangential cutting coefficients. More in details, the first term considers the difference in terms of the shear contribution to chip formation, while the second one takes into account the different tribological conditions between the cutting edge and the processed material (i.e. friction, ploughing).

$\Delta P_{c u t t_{j}-d y}[\%]=100 \cdot \frac{\left(K_{t c_{j}}-K_{t t_{d y y}}\right) \cdot f_{z} \cdot\left(\frac{a_{e}}{D}\right)+\frac{1}{2} \cdot\left(K_{t e_{j}}-K_{t e_{d y}}\right) \cdot \operatorname{acos}\left(1-\frac{2 a_{e}}{D}\right)}{K_{t t_{d y}} \cdot f_{z} \cdot\left(\frac{a_{e}}{D}\right)+\frac{1}{2} \cdot K_{t e_{d y}} \cdot \operatorname{acos}\left(1-\frac{2 a_{e}}{D}\right)}$

Equation 13 can be rewritten considering the cryogenicdry comparison (Eq. 14) and the conventional-dry comparison respectively (Eq. 15).

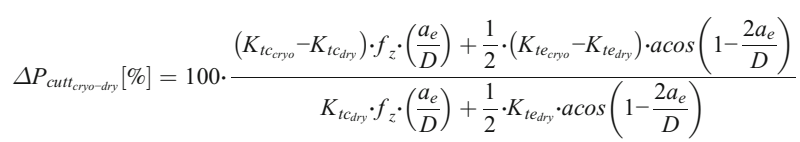

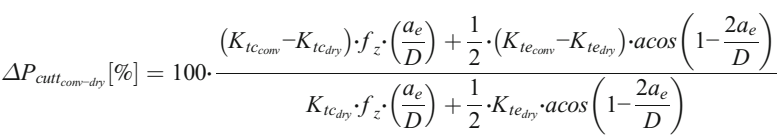

\subsubsection{Cutting process model parameters identification}

The identification of the cutting coefficients is typically performed exploiting experimental cutting force measurements, through a linear regression procedure. The force along the main machine axis direction can be experimentally measured $\left(F_{x}(t), F_{y}(\mathrm{t})\right.$ and $\left.F_{z}(t)\right)$ through force dynamometer, and the linked average contributions $\left(\overline{F_{x}}, \overline{F_{y}}, \overline{F_{z}}\right.$ ) can even be analytically formulated (Eq. 16) [74].

$$
\begin{gathered}
\overline{F_{x}}=\left\{\frac{Z \cdot a_{p} \cdot f_{z}}{8 \pi} \cdot\left[K_{t c} \cdot \cos 2 \varphi_{i}-K_{r c}\left(2 \varphi_{i}-\sin 2 \varphi_{i}\right)\right]+\frac{Z \cdot a_{p}}{2 \pi} \cdot\left[-K_{t e} \cdot \sin \varphi_{i}+K_{r e} \cdot \cos \varphi_{i}\right]\right\}_{\varphi_{s t}}^{\varphi_{e x}} \\
\overline{F_{y}}=\left\{\frac{Z \cdot a_{p} \cdot f_{z}}{8 \pi} \cdot\left[K_{t c} \cdot\left(2 \varphi_{i}-\sin 2 \varphi_{i}\right)+K_{r c} \cos 2 \varphi_{i}\right]-\frac{Z \cdot a_{p}}{2 \pi} \cdot\left[K_{t e} \cdot \cos \varphi_{i}+K_{r e} \cdot \sin \varphi_{i}\right]\right\}_{\varphi_{s t}}^{\varphi_{s t}} \\
\overline{F_{z}}=\frac{Z \cdot a_{p}}{2 \pi} \cdot\left[-K_{a c} \cdot f_{z} \cdot \cos \varphi_{i}+K_{a e} \cdot \varphi_{i}\right]_{\varphi_{s t}}^{\varphi_{e x}}
\end{gathered}
$$

For the analysed milling operation, we can consider Eq. 17.

$$
\begin{gathered}
\varphi_{s t}=0 ; \varphi_{e x} \\
\varphi_{e x}=\operatorname{acos}\left(1-\frac{2 a_{e}}{D}\right)
\end{gathered}
$$

According to the multiple linear regression theory [75], the unknown cutting force coefficients can be estimated by solving Eq. 18:

$\boldsymbol{y}=\boldsymbol{X} \cdot \boldsymbol{\beta}+\epsilon$

where $\boldsymbol{\beta}$ is the vector of the unknown $(p=6)$ regression coefficients (cutting coefficients), $\boldsymbol{X}$ the vector of the regressor variables and $y$ the vector that contains the response variables (average cutting forces). For the considered case, they can be formalized using Eq. 19. $\epsilon$ is the random error. $n$ is the number of cutting tests that is the number of different experimental cutting conditions.
As adequately described in Section 2.1.2, six different cutting conditions $(n=6)$ were tested for each tested CL solution.

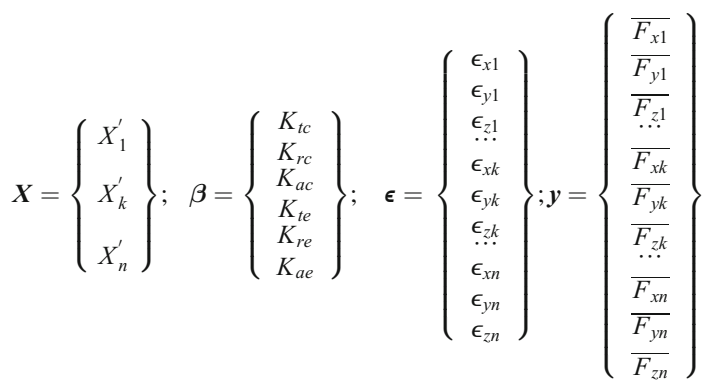

The k-th element $X_{k}$ of vector $\boldsymbol{X}$ can be properly formulated using Eq. 16 and Eq. 20. 


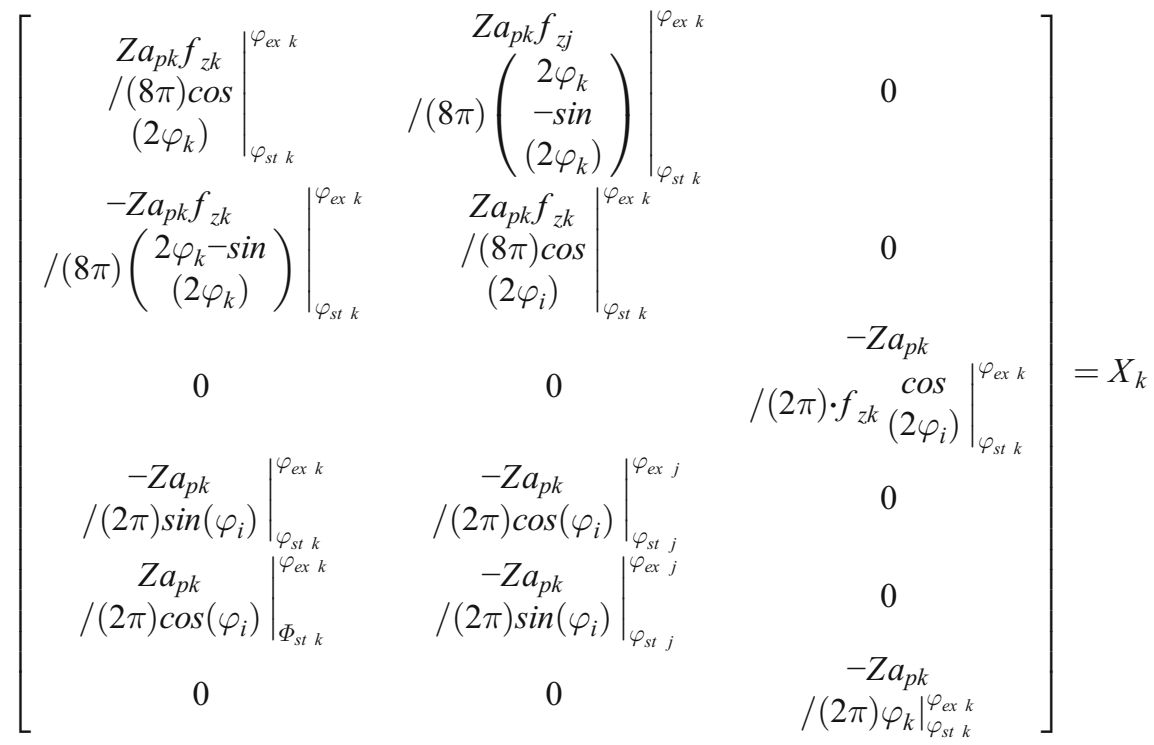

The minimization of the least square $L=\boldsymbol{\epsilon}^{\prime} \boldsymbol{\epsilon}$ brings to the unknown parameters (Eq. 21).

$\widehat{\boldsymbol{\beta}}=\left(\boldsymbol{X}^{\prime} \boldsymbol{X}\right)^{-1} \boldsymbol{X}^{\prime} \boldsymbol{y}$

Moreover, it was computed the confidence interval of each estimated $\widehat{\beta}_{q}$ parameter (Eq. 22):

$$
\beta_{q}-t_{\frac{\alpha}{2}, 3 n-p} \sqrt{\widehat{\sigma}^{2} C_{q q}} \leq \beta_{q} \leq \widehat{\beta}_{q}+t_{\frac{\alpha}{2}, 3 n-p} \sqrt{\widehat{\sigma}^{2} C_{q q}} ; C_{q q}=\operatorname{diag}\left(\boldsymbol{X}^{\prime} \boldsymbol{X}\right)^{-1} ; \widehat{\sigma}^{2}=\frac{\boldsymbol{y}^{\prime} \boldsymbol{y}-\widehat{\boldsymbol{\beta}}^{\prime} \boldsymbol{X}^{\prime} \boldsymbol{y}}{3 n-p}
$$

where $C_{q q}$ is the $q q^{\text {th }}$ element of the $\left(\boldsymbol{X}^{\prime} \boldsymbol{X}\right)^{-1}$ matrix, $\widehat{\sigma}^{2}$ the estimated variance and $t_{\frac{\alpha}{2}, 3 n-p}$ is the t-Student with $3 n-p$ degree of freedom with a confidence level $\alpha$.

In order to analyse what are the cutting coefficients more sensitive to CL, a series of 2-sample $t$ test considering the $\mathrm{j} 1-\mathrm{j} 2$ pairs were performed using Eq. 23 [75]. More specifically, the following pairs were considered: dry-conventional cooling, cryogenic-conventional and dry-cryogenic. For each 2sample $t$, the $p$ value was estimated. $\nu_{q}$ is the number of degrees of freedom.

$$
t_{0-q}=\frac{\widehat{\beta}_{q-j 1}-\widehat{\beta}_{q-j 2}}{\sqrt{\frac{C_{q q-j 1}}{n_{j 1}}+\frac{C_{q q-j 2}}{n_{j 2}}}} \nu_{q}=\frac{\left(\frac{C_{q q-j 1}}{n_{j 1}}+\frac{C_{q q-j 2}}{n_{j 2}}\right)^{2}}{\frac{\left(\frac{C_{q q-j 1}}{n_{j 1}}\right)^{2}}{n_{j 1}-1}+\frac{\left(\frac{C_{q q-j 2}}{n_{j 2}}\right)^{2}}{n_{j 2}-1}}
$$

\subsubsection{Experiments and mechanistic model parameters identification}

A Mandelli machine with a horizontal spindle (Fig. 3a) was used for the cutting tests. The machine was equipped with a Capellini Xevo electro-spindle with the maximum available torque of $160 \mathrm{Nm}$, and it can achieve up to $\Omega=8000 \mathrm{rev} / \mathrm{min}$. Both LN and lubricant were injected to the cutting zone through the nozzles of a commercial indexable cutter. For what concerns cryogenic cutting, a specific delivery system and a cryogenic head were used Fig. 3b).

The cutting forces were measured through the Kistler dynamometer $9255 \mathrm{~B}$ with the charge amplifier type 5070A. Preliminary dynamic tests on the dynamometer/piece system were performed in order to estimate the available bandwidth for the force measurements $(70 \mathrm{~Hz}$ along $\mathrm{X}, 75 \mathrm{~Hz}$ along $\mathrm{Z}$ and $300 \mathrm{~Hz}$ along Y). Moreover, it was checked that the dynamometer performances were not compromised during cryogenic cutting since the dynamometer temperature was in the suggested working range. This was guaranteed machining the upper part of the piece (far from the dynamometer (Fig. 3a)) and using a properly designed system form vacuuming the evaporated nitrogen from the machine tool working area. A similar verification was made performing temperature measurements on the spindle side in order to prevent any spindle bearing damage.

The tool used for the test was an indexable $(Z=2)$ commercial cutter (R390-020B20-11L) designed and manufactured by Sandvik Coromant. The nozzles diameter is equal to $2.5 \mathrm{~mm}$. The tool was suitable both for contouring and for slotting due to its lead angle $\chi=90^{\circ}$. The utilized inserts, the R390-11 T3 08M-MM S30T type is featured with 


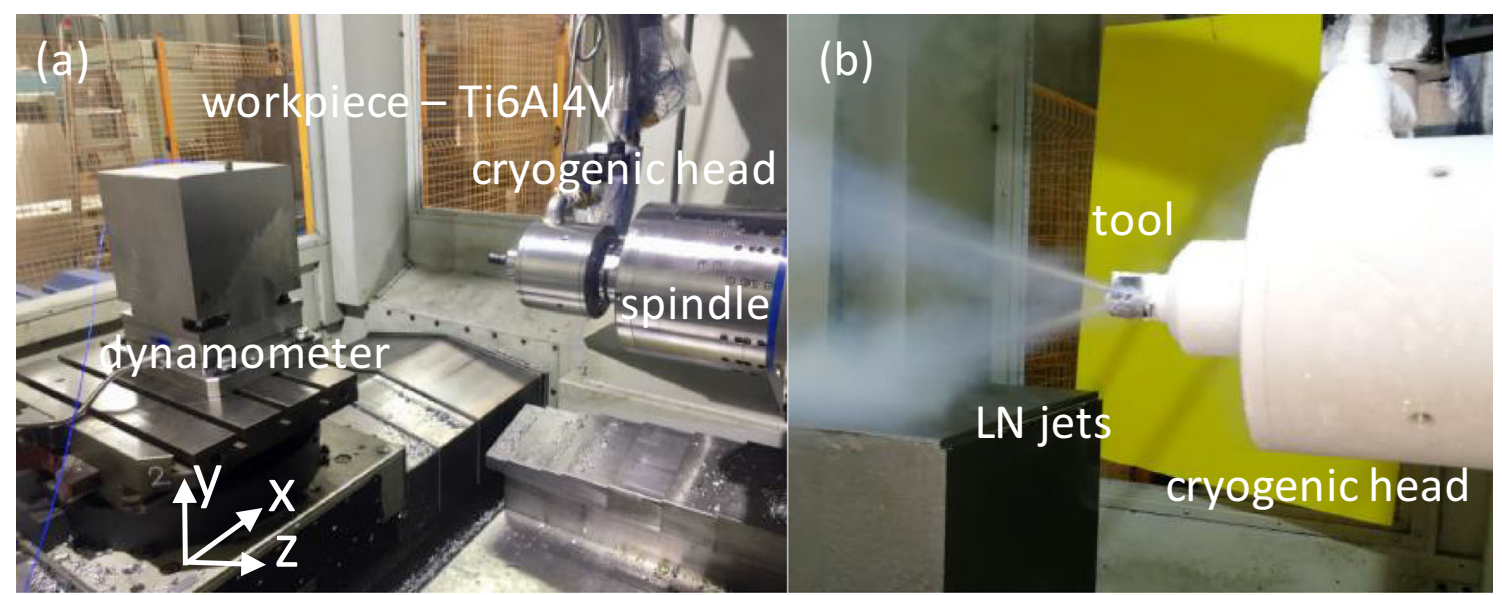

Fig. 3 Experimental set-up for cutting tests: $\mathbf{a}$ force sensor and $\mathbf{b}$ cryogenic head

a physical vapour deposition PVD TiAlN coating developed by Sandvik Coromant, and it is an industrial state-of-art solution for processing Ti6A14V or other HRAs. Details on the tool geometry and on the cutting tool profile can be observed in Fig. $4 \mathrm{a}$ and $\mathrm{b}$. More specifically, Fig. $4 \mathrm{~b}$ shows the analysis performed with the scanning electron microscope SEM of the cross section of the cutting edge where it is clearly visible the TiAlN coating. According to the results already achieved, Fig. $4 \mathrm{c}$ and $\mathrm{d}$ show the estimated velocity profile and the liquid volumetric ratio close to the insert [45]. For what concerns the LN consumption, the overall mass flow rate $\dot{m}_{L N}$ was roughly measured through differential measurements of the weight of the dewar during cutting tests. Setting the LN pressure inside the dewar to press $=3.5$ bar, the mass flow rate was $\overline{\dot{m}_{L N}} \cong 45 \mathrm{~kg} / \mathrm{h}$. Regarding conventional cutting, the lubricant flow rate was measured through a flow sensor $\left(\overline{Q_{l u b}}=20.8 \mathrm{l} / \mathrm{min}\right)$, refer to Section 2.3.2 for more details.

An experimental campaign of milling tests was adequately designed for estimating the cutting coefficients $\widehat{\boldsymbol{\beta}}_{\boldsymbol{j}}$ for each cooling lubricating condition " $\mathrm{j}$ ”. As suggested by [74], the main cutting parameter to be varied for this purpose is the feed $f_{z}$. In this research, $f_{z}$ was set in a range from 0.08 to $0.2 \mathrm{~mm} /$ tooth, and three discrete values were considered. Although the mechanistic model does not consider the cutting velocity dependence, two values for $\mathrm{v}_{\mathrm{c}}$ were considered $(50 \mathrm{~m} / \mathrm{min}$ and $70 \mathrm{~m} / \mathrm{min}$ ). Without any loss of generality, other milling parameters were considered blocked factors (axial depth of cut $a_{p}=3 \mathrm{~mm}$ and radial depth of cut $a_{e}=5 \mathrm{~mm}$ ).

As summarized in Table 2, the combination of the considered factors $\left(f_{z}\right.$, three levels; $v_{c}$, two levels) brought to $n=6$ different cutting conditions that were tested (in random order) just in a single pass in order to limit the tool wear. For this purpose, specific part programs in G-code in which the spindle speed $\Omega$ and the feed rate $V_{f}=f_{z} Z \Omega$ were changed according to run order were developed. A similar strategy was adopted even for conventional cutting (Table 3). For each tested CL condition, brand-new inserts were used to prevent any effects due to the tool wear. Even the wear occurred at the end of each single pass can be considered negligible. Indeed, no specific trends in the cutting forces are visible in Fig. 5.

In Fig. 5, the measured cutting forces acquired during the execution of conventional cutting tests were reported. Similar results were also available for dry and cryogenic cutting. The tested cutting conditions $(n=6)$ are clearly visible in Fig. 5a
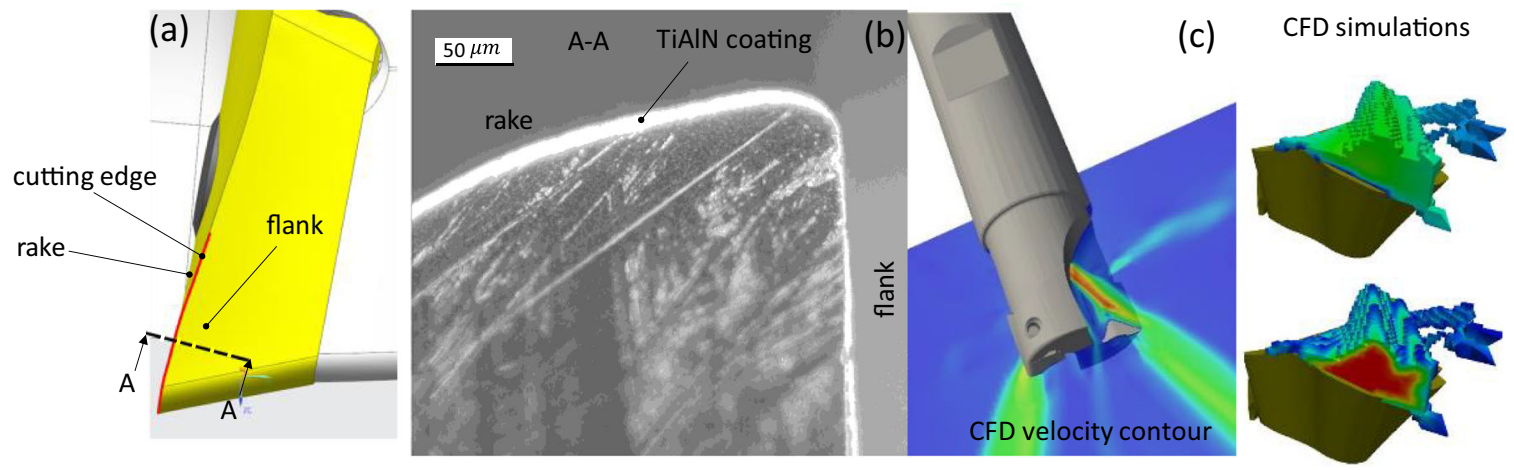

(d)

Fig. 4 Tool geometry and simulation of the adopted cryogenic cooling conditions [45]. a) is the insert geometry b) the cross-section of the cutting edge (Scanning Electron Microsccope) c) CFD velocity contour d) CFD simulation results (close to the cutting area) 
Table 2 Cutting test parameters and run order (cryogenic and dry cutting tests)

\begin{tabular}{lllllll}
\hline Run order & 2 & 3 & 4 & 6 & 5 & 1 \\
\hline$f_{z}[\mathrm{~mm} / \mathrm{tooth}]$ & 0.08 & 0.15 & 0.20 & 0.08 & 0.15 & 0.20 \\
$v_{c}[\mathrm{~m} / \mathrm{min}]$ & 50 & 50 & 50 & 70 & 70 & 70 \\
$\Omega[\mathrm{rpm}]$ & 796 & 796 & 796 & 1114 & 1114 & 1114 \\
$V_{f}[\mathrm{~mm} / \mathrm{min}]$ & 127 & 239 & 318 & 178 & 334 & 446 \\
\hline
\end{tabular}

Depth of cut $a_{p}=3 \mathrm{~mm}$, radial tool-workpiece engagement $a_{e}=5 \mathrm{~mm}$

where the forces along the machine axis $\left(F_{x}, F_{y}\right.$ and $\left.F_{z}\right)$ are reported. In Fig. $5 \mathrm{~b}$, details of $F_{y}$ at $v_{c}=50 \mathrm{~m} / \mathrm{min}$ and adopting $f_{z}=0.2 \mathrm{~mm} /$ tooth can be appreciated.

Some preliminary considerations on the measured cutting forces need to be carried out. In order to analyse the effect of the CL technology on the cutting mechanisms, the cutting forces along $y$ axis associated to dry, cryogenic and conventional milling were compared in Fig. 6b. Before comparing the forces, an average processing was first carried out: several cutting force profiles $F_{k_{r}}(t)$ (i.e. Fig. 6a) were synchronized and averaged using Eq. 24. $k$ refers to the machine direction, $r$ is the index for the cutting force profile and $m=30$ is the number of profiles used for the averaging process. Moreover, the confidence interval $95 \%$ can even be computed using a relationship similar to the one reported in Eq. 22 and knowing $\widehat{\sigma}^{2}{ }_{F_{k}}(t)$ (see Eq. 24).

$$
\begin{aligned}
F_{k}(t) & =\frac{1}{m} \sum_{r=1}^{r=m} F_{k_{r}}(t) ; \widehat{\sigma}_{F_{k}}^{2}(t) \\
& =\frac{1}{m-1} \sum_{r=1}^{r=m}\left(F_{k_{r}}(t)-F_{k}(t)\right)^{2}
\end{aligned}
$$

It is worth noting that CL strategy heavily affected the experimental cutting forces. More specifically, it can be observed that cryogenic cooling made the cutting forces lower. This could bring to interesting results in terms of energy saving with respect to dry cutting, at least considering the cutting process level. So far, no similar studies focused on cutting forces in cryogenic milling have been found. Some research works (dealing with other machining processes) show

Table 3 Cutting test parameters and run order (conventional cooling tests)

\begin{tabular}{lllllll}
\hline run order & 2 & 3 & 4 & 6 & 5 & 1 \\
\hline$f_{z}[\mathrm{~mm} /$ tooth $]$ & 0.14 & 0.057 & 0.15 & 0.11 & 0.2 & 0.08 \\
$v_{c}[\mathrm{~m} / \mathrm{min}]$ & 70 & 70 & 50 & 70 & 50 & 50 \\
$\Omega[\mathrm{rpm}]$ & 1114 & 1114 & 796 & 1114 & 796 & 796 \\
$V_{f}[\mathrm{~mm} / \mathrm{min}]$ & 318 & 127 & 239 & 239 & 318 & 127 \\
\hline
\end{tabular}

Depth of cut $a_{p}=3 \mathrm{~mm}$, radial tool-workpiece engagement $a_{e}=5 \mathrm{~mm}$ conflicting results (i.e. $[60,63,68,69]$. This could be related to the fact that the effects of the cryogenic cooling are very sensitive to the experimental set-up and to the LN injection specifications.

In order to identify the cutting coefficients $\widehat{\boldsymbol{\beta}}_{\boldsymbol{j}}$ (Eq. $21)$ the measured cutting forces, in all the tested conditions, were averaged, and both the $\boldsymbol{y}_{\boldsymbol{j}}$ vector and the matrix $\boldsymbol{X}_{\boldsymbol{j}}$ were arranged according to Eq. 19 and Eq. 20 . The average cutting forces and the regression curves were reported in Fig. 7. A good fitting is also confirmed by $R^{2}$ and $R_{\text {adj }}^{2}$ that are higher than 0.991 in all the cases. The hypotheses on the residuals (normality, homogeneity of the variance, independency of the residuals) were also checked. The identified parameters (Table 4), together with the 95\% confidence intervals, of the mechanistic model are shown in Fig. 8.

The analysis confirms that the LN2 strongly affected the cutting mechanisms and the tribological aspects.

More in details, the results of the 2-sample $t$ test carried out with Eq. 23 are reported in Fig. 9. The analysis shows that $K_{t e}$ and $K_{r e}$ are both statistically affected by the CL since the associated $p$ values are very low. It can be even observed that $K_{t c}$ cannot be considered different only for the dryconventional pair.

$K_{t c}$, that is, the cutting coefficient used for considering the shear effect in the chip formation, was considerably reduced by the cryogenic coolant both with respect to dry and conventional cutting. This agrees with the results reported in [71] that used the coefficients for assessing the turning stability but disagrees with some considerations found in literature.

For instance, [72] guessed that cold strengthening of the material makes the cutting forces increasing, but generally this effect is contrasted and dominated by the friction reduction that makes the cutting forces reducing. Indeed, in the present research, such friction reduction was observed too. This was confirmed by the severe reduction noted in $K_{t e}$ and $K_{r e}$. An plausible explanation of the origin of such effect was provided by [70]. The reduction of the coefficients was observed even for conventional cooling with respect to dry cutting even if it was expected due to the presence of the lubricant. Some analysed literature works (i.e. $[32,68]$ ) guessed that the $\mathrm{LN}$ tends to evaporate, and consequently it creates a hydraulic cushion that reduces the friction between the contact surfaces. This research confirms the results found by [63] in turning that observed the reduction of the main force but a slight increment of the thrust force. Although milling is a different process, a similar effect was observed on the tangential force and the radial force as inferred by the identified coefficients $K_{t c}$ and $K_{r c}$. 

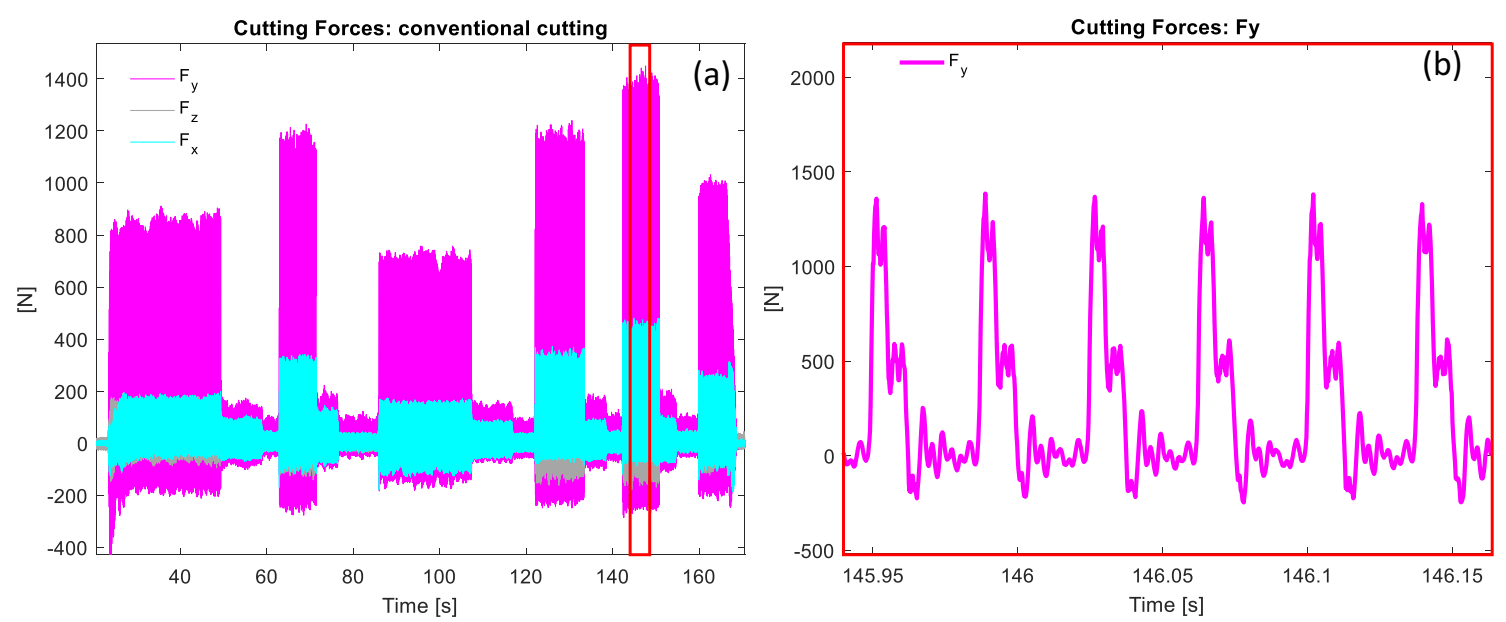

Fig. 5 Cutting force measurements during conventional cutting tests (a) $\left(a_{p}=3 \mathrm{~mm}, a_{e}=5 \mathrm{~mm}\right)$ and (b) $\mathrm{F}_{\mathrm{y}} \operatorname{details} f_{z}=0.2 \mathrm{~mm} / \mathrm{tooth} v_{c}=50 \mathrm{~m} / \mathrm{min}$

As a confirmation of the adequacy of the proposed modelling approach, in Fig. 10 the experimental and the simulated cutting forces (with the identified coefficients, Table 4) along $X$ and $Y$ were compared. The experimental forces only exhibit additional dynamics most likely linked to the machine and dynamometer resonances. Similar results were also achieved for dry and cryogenic cutting. The model validation was performed considering the following cutting parameters: $v_{c}=50 \mathrm{~m} / \mathrm{min}, f$ $z=0.2 \mathrm{~mm} /$ tooth,$a_{e}=5 \mathrm{~mm}$ and $a_{p}=3 \mathrm{~mm}$.

\subsection{Power assessment at the spindle level}

To perform a power assessment at the spindle level, the contribution of the spindle (in the analysed case a permanent magnet synchronous motors PMSM, brushless) needs to be added to the cutting power that was already formalized. For this purpose, a spindle system model was developed (Section 2.2.1).

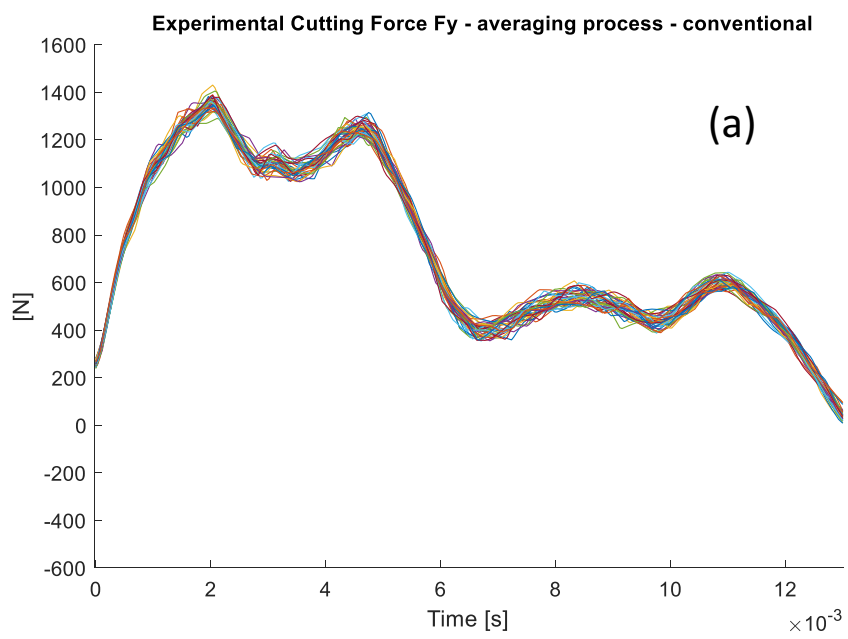

\subsubsection{Spindle modelling}

It was assumed, according to [76, 77], that the mechanical power $P_{m e c} c_{\text {spindle }}$ and the Joule losses Ploss $s_{\text {spindle }}$ are the main contributions to the spindle power $P_{\text {spindle }}$ (Eq. 25).

$P_{\text {spindle }}=$ Pmec $_{\text {spindle }}+$ Ploss $_{\text {spindle }}$

Moreover, according to Eq. 26, static friction (associated to the parameter $\mu_{s}$ ), viscous friction (linked to $\mu_{v}$ ), the inertial term (through $J_{\text {spindle }}$ ) and the one linked to the cutting torque Torque $_{\text {cut }}$ all contribute to the mechanical power $P m e c_{\text {spindle }}$ computation.

$$
\begin{aligned}
& \text { Pme }_{\text {spindle }} \\
& \quad=\left(\mu_{s} \cdot \operatorname{sign}\left(\omega_{\text {spindle }}\right)+\mu_{v} \cdot \omega_{\text {spindle }}+J_{\text {spindle }} \cdot \dot{\omega}_{\text {spindle }}+\text { Torque }_{\text {cut }}\right) \cdot \omega_{\text {spindle }} \\
& =k_{t_{\text {spindle }}} \cdot i_{q-r m s_{\text {spindle }}} \cdot \omega_{\text {spindle }}
\end{aligned}
$$

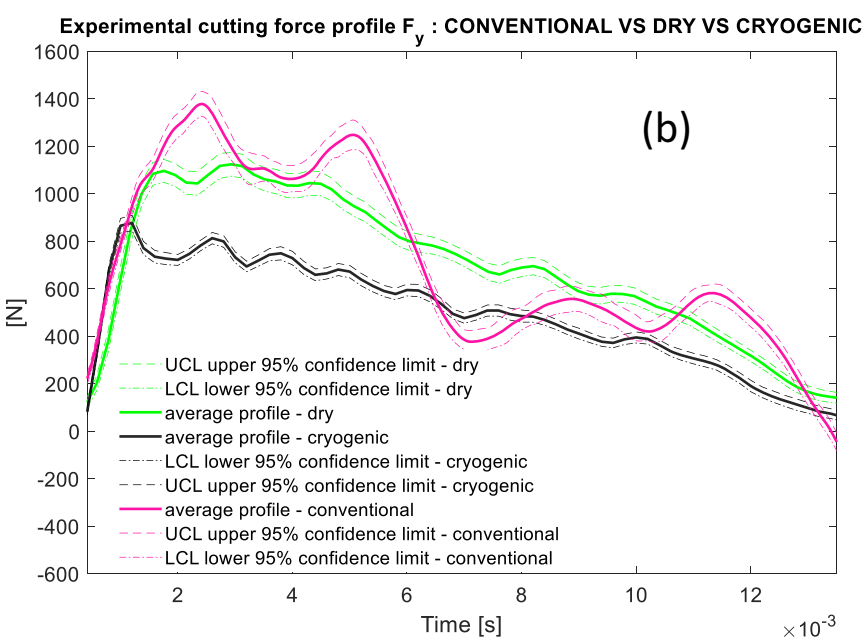

Fig. 6 (a) Forces on teeth and (b) cryogenic-dry-conventional cutting force comparison 
Table 4 Identified cutting coefficients - dry-cryogenic - conventional cooling

\begin{tabular}{llll}
\hline $\begin{array}{l}\text { Cutting } \\
\text { coefficients }\end{array}$ & $\widehat{\beta}_{\mathrm{q}-\text { dry }}$ & $\widehat{\beta}_{\mathrm{q}-\text { cryo }}$ & $\widehat{\beta}_{\mathrm{q}-\text { conv }}$ \\
\hline$K_{t c}[\mathrm{MPa}]$ & 1868.3 & 1623.1 & 1866.91 \\
$K_{r c}[\mathrm{MPa}]$ & 671.5 & 688.9 & 615.75 \\
$K_{a c}[\mathrm{MPa}]$ & -99.8 & -20.6 & -38.72 \\
$K_{t e}[\mathrm{~N} / \mathrm{mm}]$ & 44.4 & 12.9 & 36.41 \\
$K_{r e}[\mathrm{~N} / \mathrm{mm}]$ & 115.8 & 62.6 & 93 \\
$K_{a e}[\mathrm{~N} / \mathrm{mm}]$ & 11.7 & 11.2 & 1866.91 \\
\hline
\end{tabular}

The cutting torque Torque $_{\text {cut }}$ is directly computed from the cutting power as follows: Torque ${ }_{\text {cut }}=P_{\text {cut }} /$ $\omega_{\text {spindle. }}$ The mechanical power can even be calculated considering the torque constant $k_{t_{\text {spindle }}}$ and the root mean square (rms) quadrature current $i_{q-r m s_{\text {spindle }}}$ [78]. The Joule losses can be analytically formalized through Eq. 27 where $R_{\text {spindle }}$ is the motor phase resistance and $i_{q_{\text {spindle }}}$ is the spindle quadrature current.

Ploss $_{\text {spindle }}=R_{\text {spindle }} \cdot i_{q_{\text {spindle }}}^{2}$

Considering Eq. 28, assuming that during cutting the iner$i_{q_{\text {spindle }}}=\sqrt{2} \cdot \frac{P m e c_{\text {spindle }}}{k_{t_{\text {spindle }}} \cdot \omega_{\text {spindle }}} ; i_{q-r m s_{\text {spindle }}}=\frac{P m e c_{\text {spindle }}}{k_{t_{\text {spindle }}} \cdot \omega_{\text {spindle }}}$

Moreover, the main affecting cutting process parameters $\left(v_{c}, a_{e} / D, f_{z}\right)$ were underlined

$P_{\text {spindle }_{j}}\left(v_{c}, a_{e} / D, f_{z}\right)$

$=\omega_{\text {spindle }} \cdot\left(\mu_{s} \cdot \operatorname{sign}\left(\omega_{\text {spindle }}\right)+\mu_{v} \cdot \omega_{\text {spindle }}+\frac{P_{\text {cut }_{j}}}{\omega_{\text {spindle }}}\right)$

$$
+R_{\text {spindle }} \cdot\left(\frac{\sqrt{2}}{K_{t_{\text {spindle }}}} \cdot\left(\mu_{s} \cdot \operatorname{sign}\left(\omega_{\text {spindle }}\right)+\mu_{v} \cdot \omega_{\text {spindle }}+\frac{P_{\text {cut }}}{\omega_{\text {spindle }}}\right)\right)^{2}
$$

Once the spindle motor power was formalized, the following power comparisons can be defined, and the power assessment can be performed (Eq. 30 and Eq. 31). Both $\Delta$ $P_{\text {spindle }_{\text {conv-dy }}}$ and $\Delta \mathrm{P}_{\text {spindle }_{\text {cyo-dry }}}$ were normalized with respect to $P_{\text {spindle }_{\text {dry }}}$.

$\Delta P_{\text {spindleconv-dy }}[\%]\left(v_{c}, a_{e} / D, f_{z}\right)$

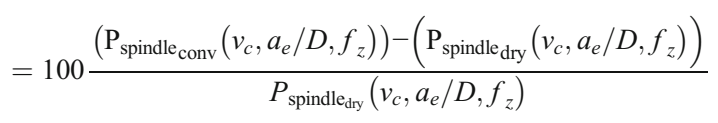

tial contribution can be neglected $\left(\dot{\omega}_{\text {spindle }}=0\right)$ and introducing the dependence on the adopted cooling condition $j$, Eq. 25 can be re-written as follows (see Eq. 29):

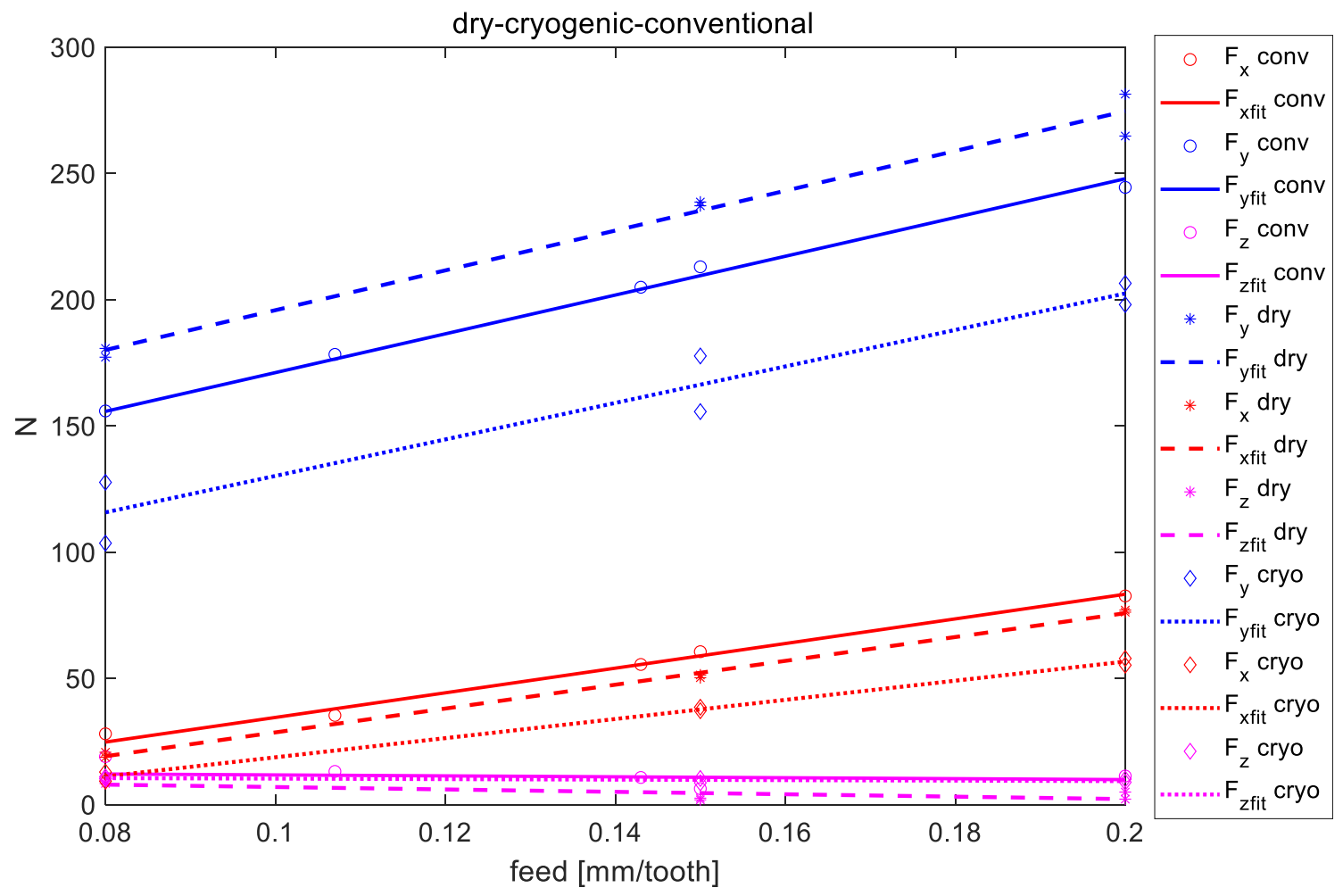

Fig. 7 Experimental average cutting forces and fitting curves: conventional cooling - dry cutting - cryogenic cooling 

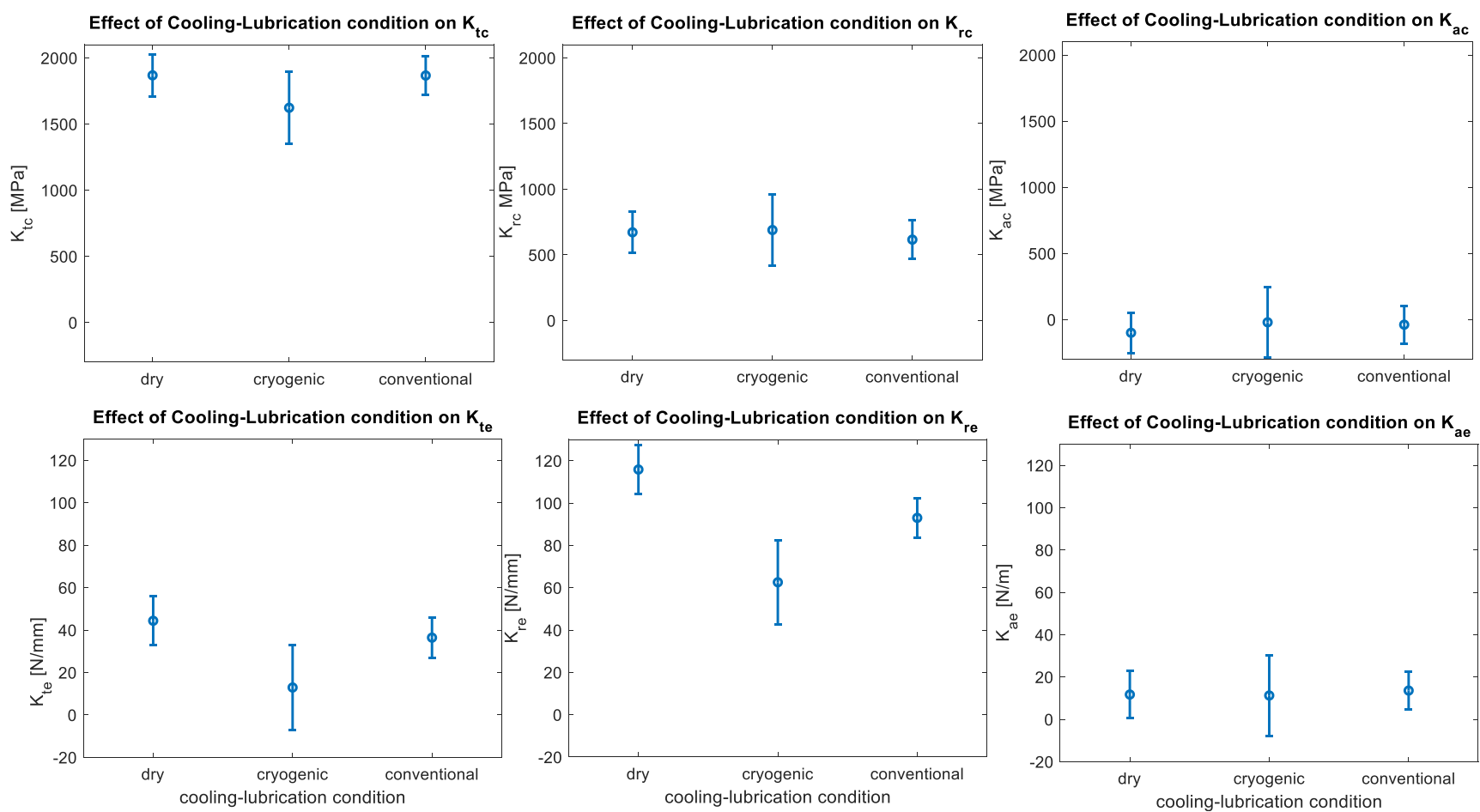

Fig. 8 Identified cutting coefficients in different cooling lubrication conditions (dry, cryogenic and conventional cooling) with the corresponding 95\% CI

$$
\begin{aligned}
& \Delta P_{\text {spindle }_{\text {cryo-dry }}}[\%]\left(v_{c}, a_{e} / D, f_{z}\right) \\
& =100 \frac{\left(\mathrm{P}_{\text {spindle }_{\text {cryo }}}\left(v_{c}, a_{e} / D, f_{z}\right)\right)-\left(\mathrm{P}_{\text {spindle }_{\text {dry }}}\left(v_{c}, a_{e} / D, f_{z}\right)\right)}{P_{\text {spindle }_{\text {dry }}}\left(v_{c}, a_{e} / D, f_{z}\right)}
\end{aligned}
$$

\subsubsection{Experiments and spindle model parameters identification}

In order to identify the spindle model parameters of Eq. 26, some experiments were carried out on Capellini

Fig. 9 Effect of the CL methodology on the identified cutting coefficients $-p$ values associated to the performed 2sample $t$ tests

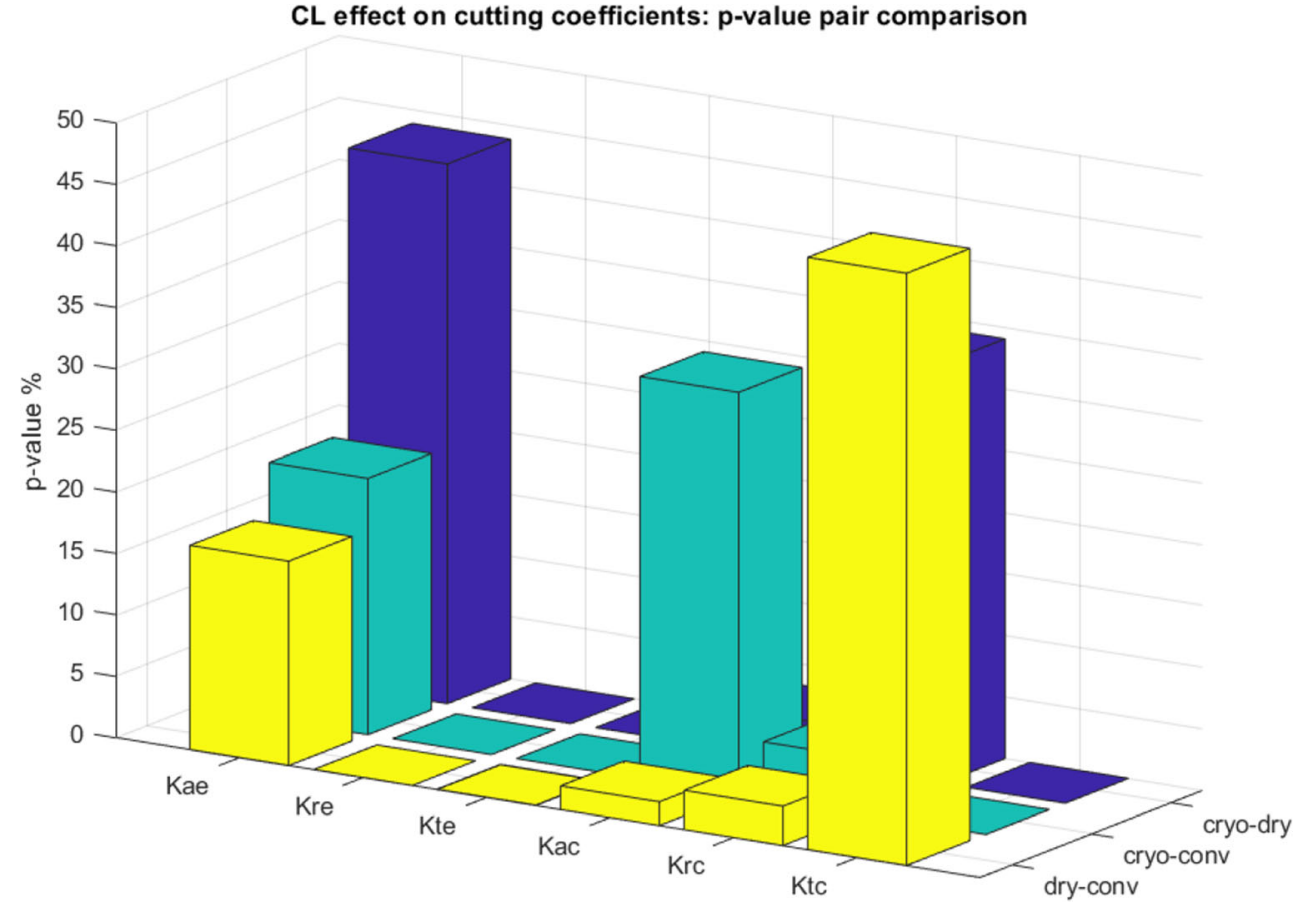


Fig. 10 Cutting force $\mathrm{X}$ and $\mathrm{Y}$ direction - experimental and simulated comparison (conventional cutting - validation point)
Conventional - Experimental Vs Simulated $-f_{z}=0.2 \mathrm{~mm} /$ tooth, $a_{e}=5 \mathrm{~mm}, a_{p}=3 \mathrm{~mm}, v_{c}=50 \mathrm{~m} / \mathrm{min}$ (validation point)

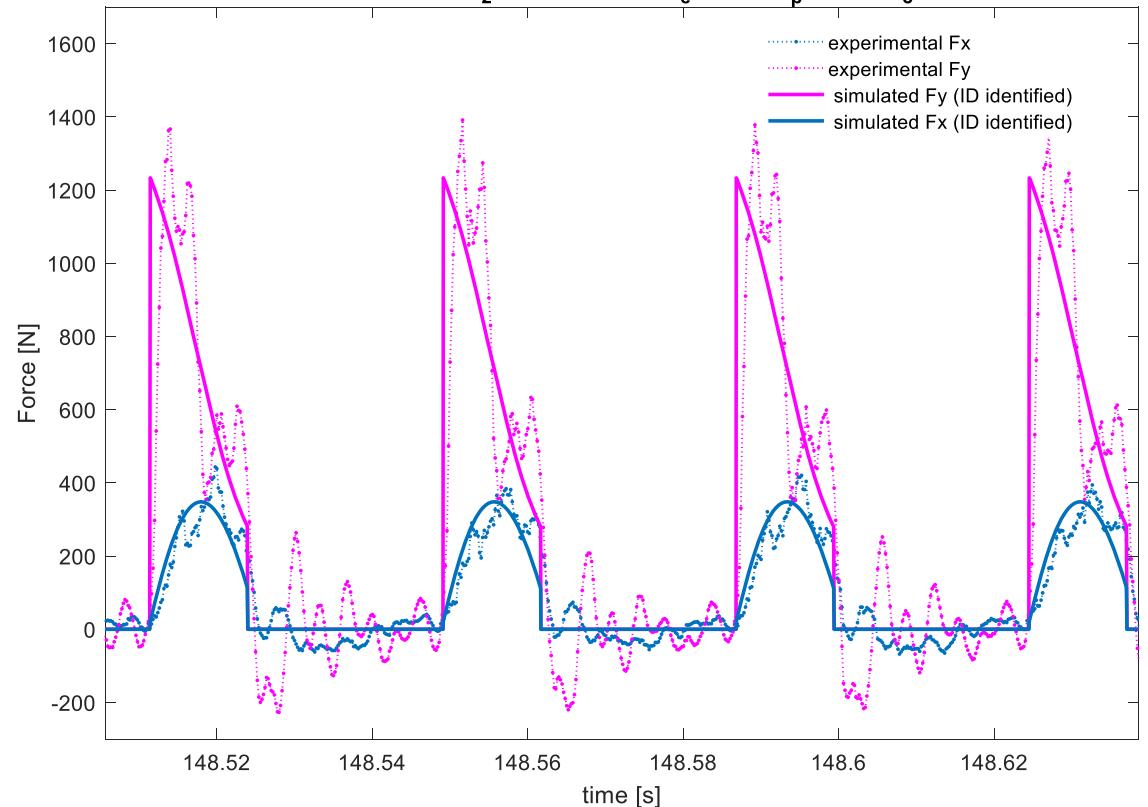

electrospindle. According to the procedure describe in [78], no load $\left(\right.$ Torque $\left._{\mathrm{cut}}=0\right)$ tests on the electrospindle were performed. Specifically, the following sequences of speeds were set to the spindle: $1000 \mathrm{rpm}, 1500 \mathrm{rpm}, 2000 \mathrm{rpm}, 2500 \mathrm{rmp}$, $3000 \mathrm{rpm}, 2500 \mathrm{rpm}, 2000 \mathrm{rpm}, 1500 \mathrm{rpm}, 1000 \mathrm{rpm}$ and $0 \mathrm{rpm}$. During the tests, the spindle speed $\omega_{\text {spindle }}$ and the $i_{q-\mathrm{rms} \text { spindle }}$ were acquired through the numerical controller (NC) (Siemens Solution Line). The spindle acceleration $\dot{\omega}_{\text {spindle }}$ was numerically computed deriving the $\omega_{\text {spindle }}$.

$$
\begin{aligned}
K_{t_{\text {spindle }}} \cdot i_{q-\mathrm{rms}_{\text {spindle }}}(t)= & \mu_{s} \cdot \operatorname{sign}\left(\omega_{\text {spindle }}(t)\right)+\mu_{v} \cdot \omega_{\text {spindle }}(t) \\
& +J_{\text {spindle }} \cdot \dot{\omega}_{\text {spindle }}(t)
\end{aligned}
$$

Rearranging Eq. 32, the unknown parameters $\boldsymbol{\beta}_{\text {spindle }}=$ $\left[\begin{array}{lll}\mu_{s} & \mu_{v} & J_{\text {spindle }}\end{array}\right]$ can be estimated through a least square regression (LSR), (Eqs. 33 and 34).

$$
\begin{aligned}
\boldsymbol{y}_{\text {spindle }} & =\boldsymbol{X}_{\text {spindle }} \cdot \boldsymbol{\beta}_{\text {spindle }} ; \widehat{\boldsymbol{\beta}}_{\text {spindle }} \\
& =\left[\begin{array}{lll}
\widehat{\mu}_{s} & \widehat{\mu}_{v} & \widehat{J}_{\text {spindle }}
\end{array}\right] \\
& =\left(\boldsymbol{X}_{\text {spindle }}^{\prime} \boldsymbol{X}_{\text {spindle }}\right)^{-1} \boldsymbol{X}_{\text {spindle }}^{\prime} \boldsymbol{y}_{\text {spindle }}
\end{aligned}
$$

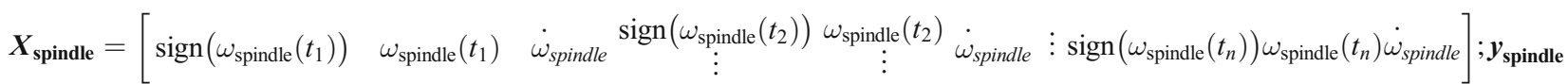

$$
\begin{aligned}
& =K_{t_{\text {spindle }}}\left[\begin{array}{c}
i_{q-\mathrm{rms}_{\text {spindle }}}\left(t_{1}\right) \\
i_{q-\mathrm{rms}_{\text {spindle }}}\left(t_{2}\right) \\
\vdots \\
i_{q-\mathrm{rms}_{\text {spindle }}}\left(t_{n}\right)
\end{array}\right]
\end{aligned}
$$

The identified parameters, together with the $K_{t_{\text {spindle }}}$ and $R_{\text {spindle }}$ are reported in Table $5 . K_{t_{\text {spindle }}}$ and $R_{\text {spindle }}$ were taken from the catalogue, but $\mathrm{R}_{\text {spindle }}$ value was also measured through a digital multimeter.

The identified model was also preliminary validated comparing the estimated electrical power $\widehat{P}_{\text {spindle }}(t)$ (Eq. 35) and the corresponding measured quantity. The comparison is reported in Fig. 11.

$$
\begin{aligned}
& \widehat{P}_{\text {spindle }}(t)=\omega_{\text {spindle }}(t) \cdot\left(\widehat{\mu}_{s} \cdot \operatorname{sign}\left(\omega_{\text {spindle }}(t)\right)+\widehat{\mu}_{v} \cdot \omega_{\text {spindle }}(t)+\widehat{J}_{\text {spindle }} \cdot \dot{\omega}_{\text {spindle }}\right) \\
& +R_{\text {spindle }} \cdot\left(\sqrt{2} \cdot \frac{1}{K_{t \text { spinde }}} \cdot\left(\widehat{\mu}_{s} \cdot \operatorname{sign}\left(\omega_{\text {spindle }}(t)\right)+\widehat{\mu}_{v} \cdot \omega_{\text {spindle }}(t)+\widehat{J}_{\text {spindle }} \cdot \dot{\omega}_{\text {spindle }}(t)\right)\right)^{2}
\end{aligned}
$$


Table 5 Spindle model parameters

\begin{tabular}{lc}
\hline Parameter & Spindle \\
\hline Static friction $\widehat{\mu}_{s}[\mathrm{Nm}]$ & 0.144 \\
Viscous friction $\widehat{\mu}_{v}[\mathrm{Nm} \cdot \mathrm{s} / \mathrm{rad}]$ & 0.018 \\
Inertia $\widehat{J}_{\text {spindle }}\left[\mathrm{kg} \cdot \mathrm{m}^{2}\right]$ & 0.041 \\
Torque constant $K_{t_{\text {spinde }}}\left[\mathrm{Nm} / \mathrm{A}_{\mathrm{rms}}\right]$ & 0.638 \\
Phase resistance $R_{\text {spindle }}[\Omega]$ & 0.017 \\
\hline
\end{tabular}

It can be noted that the estimated power matches quite well the experimentally measured power.

The electrical power absorbed by the spindle was acquired through a power meter. Figure 10 describes the adopted experimental set-up. The power meter can simultaneously acquire the powers of up to 5 three-phase loads. For each load, the three-phase currents and the corresponding voltages are acquired at a high sampling rate (up to $20 \mathrm{kHz}$ ), and the linked power can be computed. The currents are measured through LEM rings. In this specific case, the $P_{\text {spindle }}$ is computed according to Eq. 36 where it can be observed the phase currents and the associated voltages.

$$
\begin{aligned}
P_{\text {spindle }}(t)= & i_{\text {spindle }_{1}}(t) \cdot V_{\text {spindle }_{1}}(t) \\
& +i_{\text {spindle }_{2}}(t) \cdot V_{\text {spindle }_{2}}(t) \\
& +i_{\text {spindle }_{3}}(t) \cdot V_{\text {spindle }_{3}}(t)
\end{aligned}
$$

The signal acquisition was carried out by National Instruments $@$ boards, and the power processing was performed in Labview@ Fig. 12.

\subsection{Power assessment at the machine level}

In this section, the power assessment was carried out at the machine level. This means that even the feeding system was considered in the power computation. This perspective is rather common not only in literature (Rajemi et al. [79]) but even in industry (ISO 14955 - part II [80]).

Since for both dry and cryogenic cutting the feeding contribution is null, in this section, the sole feeding system model for conventional cooling was developed. Indeed, the liquid nitrogen is fed directly from the dewar without the need of supplementary auxiliaries.

\subsubsection{Conventional cooling: feeding system modelling}

In the analysed machine, the lubricant is fed in the cutting area through the inner tool nozzles by a high-pressure pump.
Fig. 11 Spindle power during noload tests: estimated (identified model ID) and experimentally measured comparison

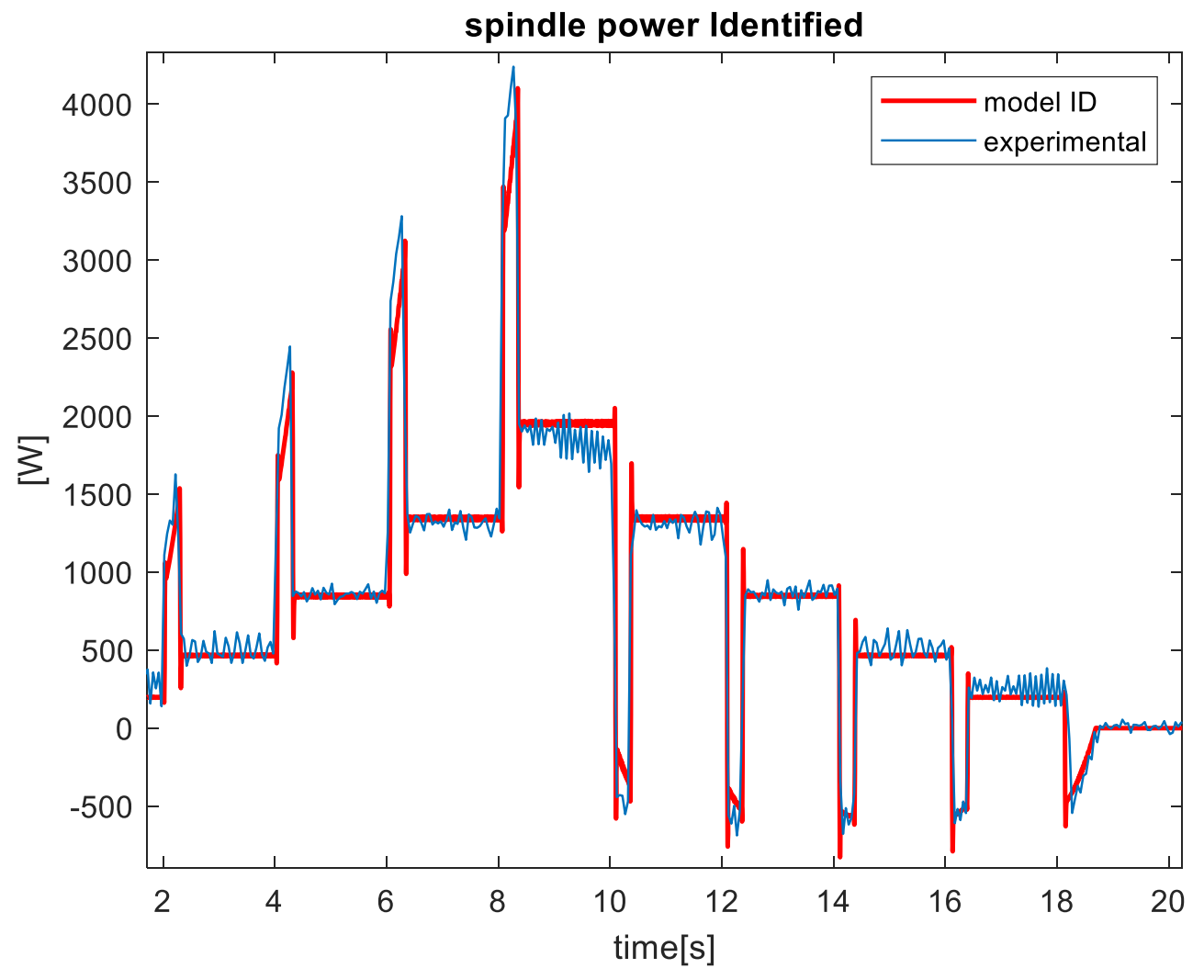


Fig. 12 Power measurements setup

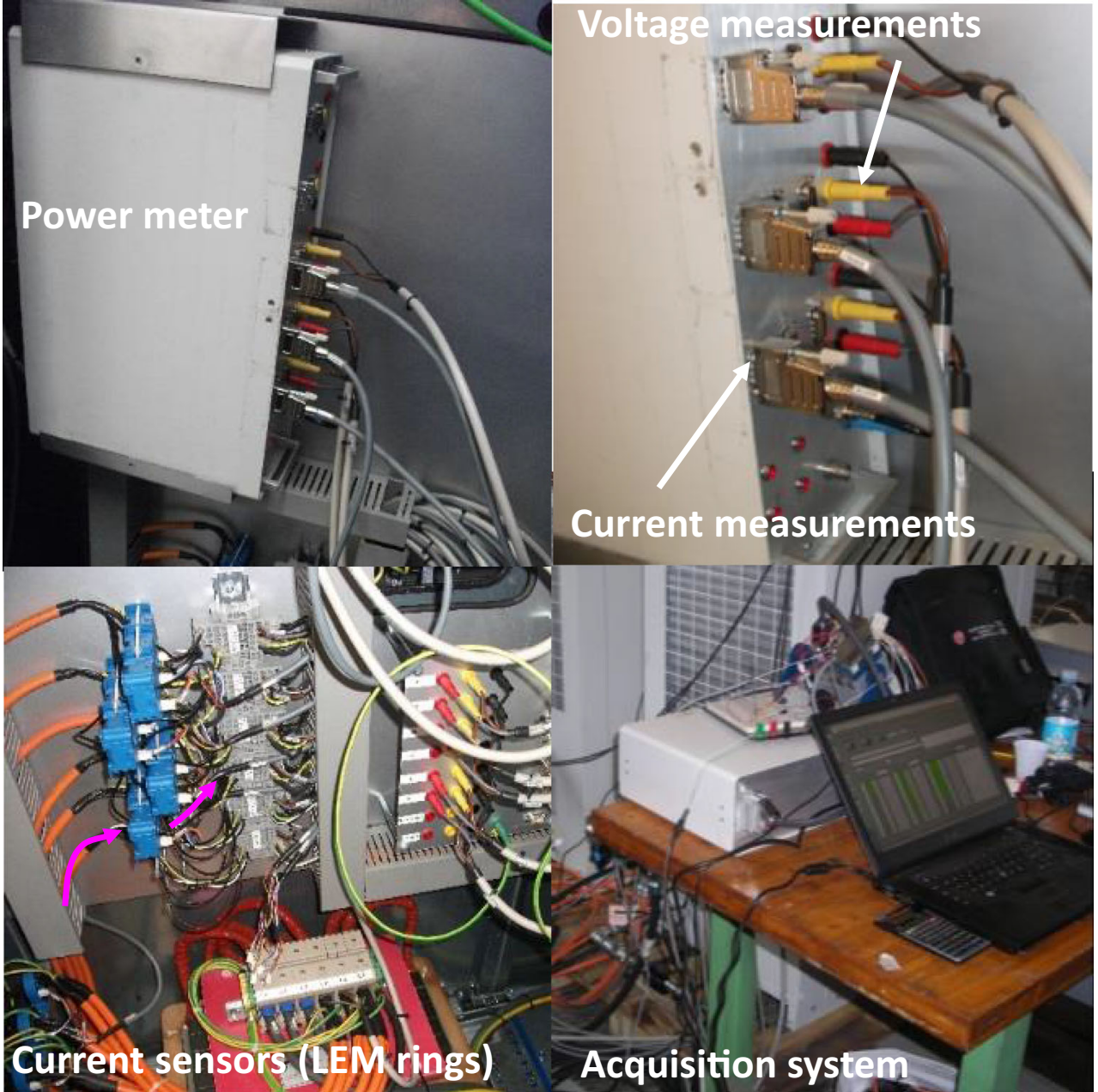

Moreover, to get back the used lubricant from the machine, a suctioning pump (Brinkmann SFL 1350) is installed on the machine. Until the wasted lubricant is fully pumped back to the sump for being reused, the suctioning pump is kept switched on. The suctioning pump is switched off when the tank (characterized by its volume $V_{\text {tank-max }}$ ) is filled.

The power consumption of the high-pressure pump depends on the working condition (in terms of flow rate $Q_{\text {lub }}$, pressure Pres $_{\mathrm{HP}}$ and power absorption $P_{\text {feed }}$ ) that is related to the specific tool mounted on the spindle. If the tool is changed, even the corresponding hydraulic load changes and consequently the corresponding working condition. The highpressure pump was described by Eqs. 37 and 38. More specifically, for the sake of simplicity, it was decided to adopt a quadratic model [81] to describe the dependence of the feeding pressure $\operatorname{Pres}_{\mathrm{HP}}$ on the lubricant volumetric flow rate $Q_{\text {lub }}$. $\operatorname{Pres}_{\mathrm{HP}}\left(Q_{\text {lub }}\right)=a_{2} \cdot Q_{\text {lub }}^{2}+a_{1} \cdot Q_{\text {lub }}+a_{0}$

$a_{0}, a_{1}$ and $a_{2}$ are the model parameters that were properly identified exploiting specifically conceived experiments (see Section 2.3.2).
For what concerns the high-pressure pump power $P_{\text {feed }}$, a linear model that describes the dependence on the pressure and flow rate product $Q_{\text {lub }} \cdot$ Pres $_{\mathrm{HP}}$ was proposed. Even in this case, the model parameters $\left(b_{0}\right.$ and $\left.b_{1}\right)$ were identified through experimental measurements (Section 2.3.2).

$P_{\text {feed }}\left(Q_{\text {lub }}\right)=b_{1} \cdot Q_{\text {lub }} \cdot \operatorname{Pres}_{\mathrm{HP}}+b_{0}$

Referring to the suctioning pump, its behaviour can be properly explained through Fig. 13 where both the amount of lubricant $V_{\text {tank }}$ in the tank and the pump power were shown $P_{\text {suct }}(t)$. According to the pump specifications, it was assumed that the power consumption is constant $P_{\text {suct-on }}$ when the pump is active. More specifically, it was shown that, depending on the $Q_{\text {lub }}$, the suctioning pump can be switched on more or less frequently. For instance, if $Q_{\text {lub1 }}<Q_{\text {lub2 }}\left(Q_{\text {lub3 }}<Q_{\text {lub1 }}\right)$, the tank is filled slower $\Delta t_{\text {off } 1}>\Delta t_{\text {off } 1}$ and it is taken less time to get back the lubricant $\Delta t_{\text {on } 1}<\Delta t_{\text {on } 2}$. For sake of clarity, $\Delta t_{\text {off }}$ is the time interval in which the suctioning pump is not working, while $\Delta t_{\text {on }}$ is the time interval in which the suctioning pump is working. The explained behaviour can be 
Fig. 13 Suction pump behaviour

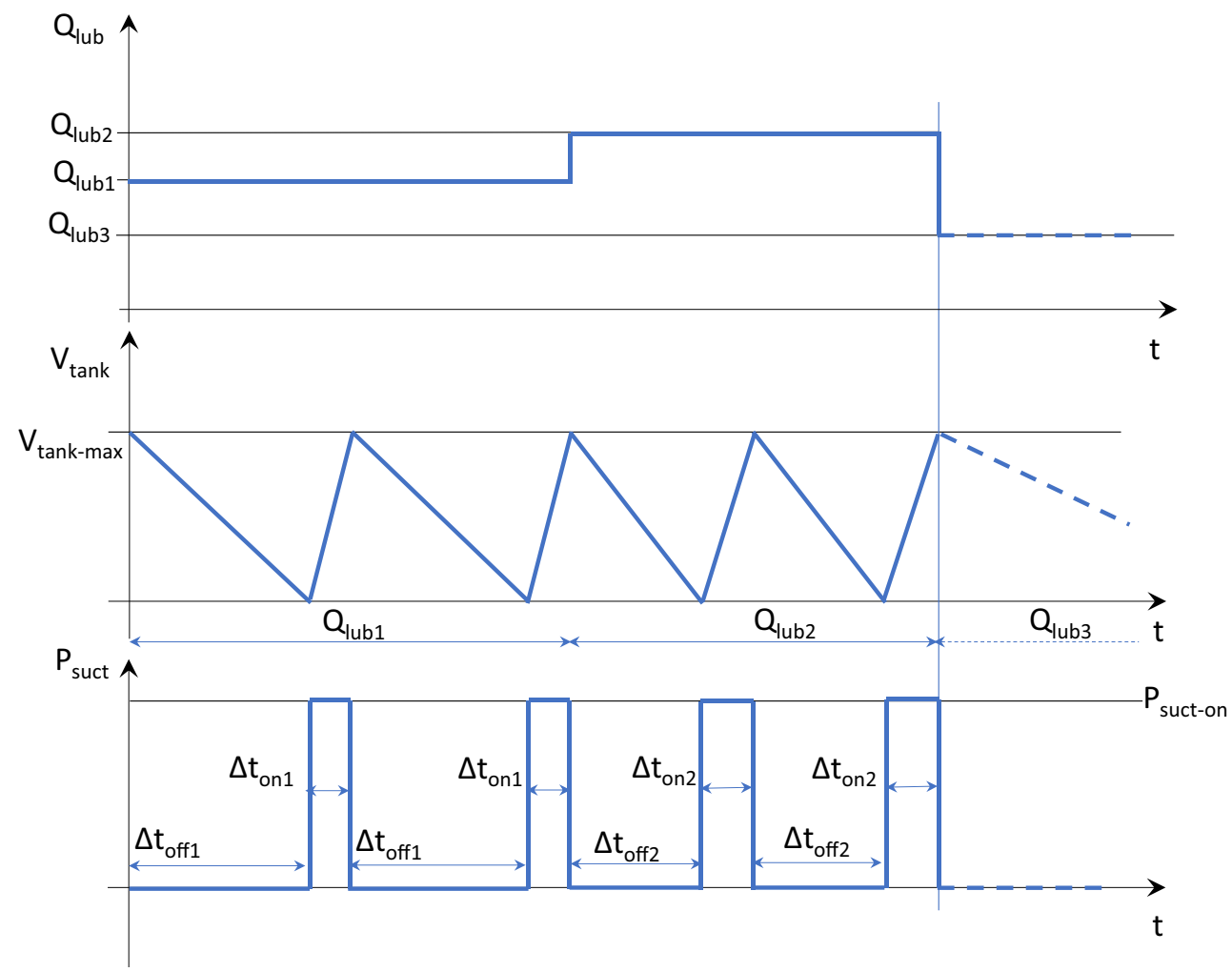

analytically described by Eqs. 39 and $40 . Q_{\text {suct }}$ is the suctioning flow rate and it was assumed to be constant.

$$
\begin{aligned}
& \Delta t_{\text {off }}=\frac{V_{\text {tank-max }}}{Q_{\text {lub }}} \\
& \Delta t_{\text {on }}=\frac{-V_{\text {tank-max }}}{Q_{\text {lub }}-Q_{\text {suct }}}
\end{aligned}
$$

The average power of the suctioning pump $P_{\text {suct-av }_{\text {conv }}}$ can be computed using Eq. 41.

$P_{\text {suct-av }_{\text {conv }}}\left(Q_{\text {lub }}\right)=\frac{P_{\text {suct-on }} \cdot \Delta t_{\text {on }}}{\Delta t_{\text {on }}+\Delta t_{\text {off }}}$

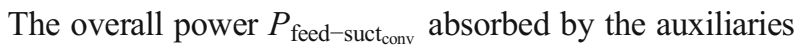
in conventional cooling can thus be expressed by Eq. 42 .

$P_{\text {feed-suct conv }}\left(Q_{\text {lub }}\right)=P_{\text {feed }}+P_{\text {suct-av }}$

Both for cryogenic cooling and dry cutting, the additional power contribution provided by the feeding system is null $\left(P_{\text {feed-suct dy }}=P_{\text {feed-suct cryo }}=0\right)$.

The power assessment at the feeding level (machine) can therefore be carried out (Eq. 43).

$\Delta P_{\text {feed }_{j} \text {-dy }}[\%]=100 \frac{\left(P_{\text {feed }_{j}}+P_{\text {spindle }_{j}}\right)-\left(P_{\text {spindle }_{\text {dry }}}\right)}{P_{\text {spindle }_{\text {dry }}}}$
If we focus first on the sole additional contribution due to the high-pressure pump, $\Delta P_{\text {feed }_{\text {conv-dy }}}[\%]$ can be expressed by Eq. 44 .

$$
\begin{aligned}
& \Delta P_{\text {feed }_{\text {conv-dy }}}[\%]\left(Q_{\text {lub }}, \overline{v_{c}}, a_{e} / D, f_{z}\right)
\end{aligned}
$$

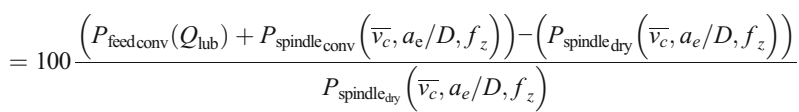

It can be observed that the power assessment can be performed considering several process-related quantities such as $Q_{\mathrm{lub}}, v_{c}, a_{e} / D$ and $f_{z}$.

Since $P_{\text {feed-suctdry }}=P_{\text {feed-suct cryo }}=0$, the cryogenic-dry power comparison at the feeding level coincides with the comparison performed at the spindle level (Eq. 45)

$\Delta P_{\text {feed }_{\text {cryo-dy }}}[\%]\left(\overline{v_{c}}, a_{e} / D, f_{z}\right) \equiv \Delta P_{\text {spindle }_{\text {cyyo-dy }}}[\%]$

Even considering the contribution to the suctioning pump, the conventional-dry comparison can be formalized through the following relationships:

$$
\begin{aligned}
& \Delta P_{\text {feed-suctear-dy }}[\%]\left(Q_{\text {lub }}, \overline{v_{c}}, a_{e} / D, f_{z}\right)
\end{aligned}
$$

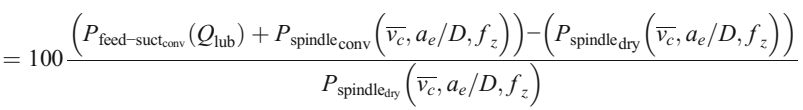


While for the cryogenic-dry comparison, the previously considerations remain valid

$\Delta P_{\text {feed-suct cryo-dry }}[\%]\left(\overline{v_{c}}, a_{e} / D, f_{z}\right) \equiv \Delta P_{\text {spindle }_{\text {cryo-dry }}}[\%]$

\subsubsection{Experiments and feeding system parameters identification}

As previously anticipated, some experiments were carried out in order to identify the model parameters of Eqs. 37 and 38 . More in details, to change the working condition of the highpressure pump, some different tools were tested. Indeed, changing the tool (with different numbers and nozzle diameters), the related hydraulic losses change and consequently do the operating condition on the characteristic curve. For each tool, the high-pressure pump was switched on, and both the volumetric flow rate $Q_{\text {lub }}$ and the feeding pressure Pres $_{\mathrm{HP}}$ were measured. The $Q_{\text {lub }}$ was measured through a Rosemount 8705 flow sensor, while the lubricant pressure was measured with a Gefran 0100 bar. The experimental set-up is reported in Fig. 14.

During the tests, even the electrical power absorbed by the high-pressure pump was acquired through the already described power meter (see Fig. 10).

The achieved experiments results are reported in Fig. 15. More in details, Fig. 15 a shows that the experimental revealed Pres $_{\mathrm{HP}}-Q_{\text {lub }}$ pairs, while in Fig. 15b, the associated power consumptions can be observed. The black points correspond to the four tested conditions changing the tools. A red circle was used to underline the nominal condition used during the already described cutting tests.

On the same pictures, it can be observed the fitted models (Eqs. 37 and 38) obtained through a LSR approach. The estimated parameters $\left(\widehat{a}_{0}, \widehat{a}_{1}, \widehat{a}_{2}, \widehat{b}_{0}\right.$ and $\left.\widehat{b}_{1}\right)$ are reported in Table 6.

For both the models, a quite high $R$-square value was obtained (close to 0.98 ). This demonstrates the adequacy of the proposed modelling approach.

For what concerns the suctioning pump, the performed power measurement confirmed the specifications reported on the catalogue $P_{\text {suct }}$. The other parameters of the model (from the pump and machine specifications) are reported in Table 7.

\subsection{Global power assessment}

In this section, the analysis was extended to an upper level. Indeed, even the power required for producing the liquid nitrogen and the lubricant was considered (CED).

The global power can thus be computed through Eq. 48.

$P_{\text {global }}=P_{\text {spindle }}+P_{\text {feed }}+P_{\text {suct }}+P_{\mathrm{CED}}$

And the generic $j^{\text {th }}$ comparison with respect to dry cutting can be formulated similar to what reported in the previous sections (Eq. 49);

$$
\begin{aligned}
& \Delta P_{\text {global }_{j \text {-dy }}}[\%] \\
& =100 \frac{\left(P_{\mathrm{CED}_{j}}+P_{\text {feed } j_{j}}+P_{\text {suct }_{j}}+P_{\text {spindle }_{j}}\right)-\left(P_{\text {spindle }_{\text {dry }}}\right)}{P_{\text {spindle }_{\text {dry }}}}
\end{aligned}
$$

where $P_{\mathrm{CED}_{j}}$ is the cumulative power demand associated to the liquid nitrogen or the lubricant.

The assessment can be performed considering the conventional-dry pair (Eq. 50):

$$
\begin{aligned}
& \Delta P_{\text {global }_{\text {conv-dy }}}[\%]\left(V_{\text {lub }}, \overline{Q_{\text {lub }}}, \overline{v_{c}}, a_{e} / D, f_{z}\right) \\
& =100 \frac{\left(P_{\mathrm{CED}_{\text {conv }}}\left(V_{\text {lub }}\right)+P_{\text {feed-suct }_{\text {conv }}}\left(\overline{Q_{\text {lub }}}\right)+\mathrm{P}_{\text {spindle }_{\text {conv }}}\left(\overline{v_{c}}, a_{e} / D, f_{z}\right)\right)-\mathrm{P}_{\text {spindle }_{\text {dry }}}\left(\overline{v_{c}}, a_{e} / D, f_{z}\right)}{P_{\text {spindle }_{\text {dry }}}\left(\overline{v_{c}}, a_{e} / D, f_{z}\right)}
\end{aligned}
$$

Fig. 14 Lubricant flow rate sensor and pressure sensor

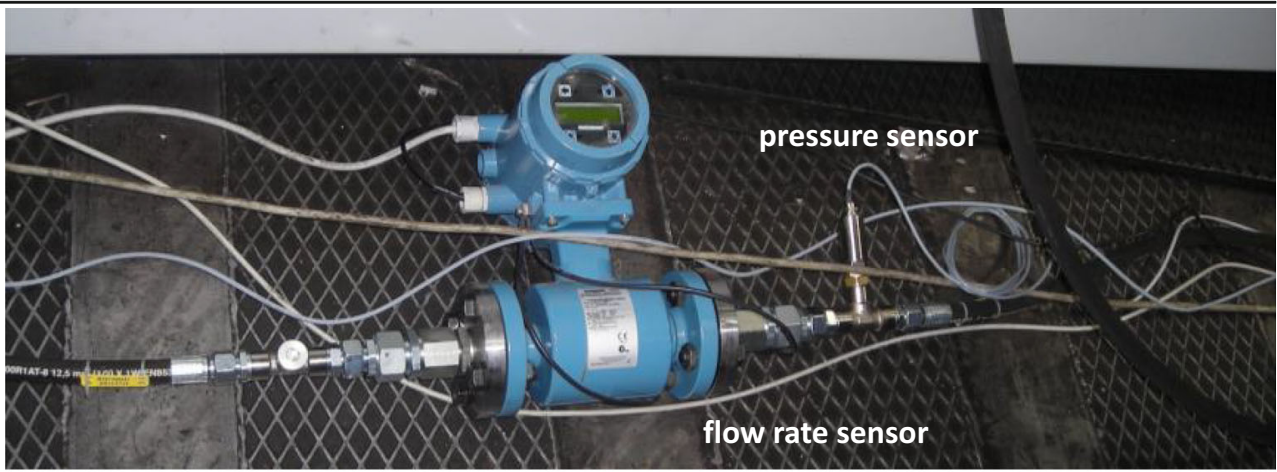



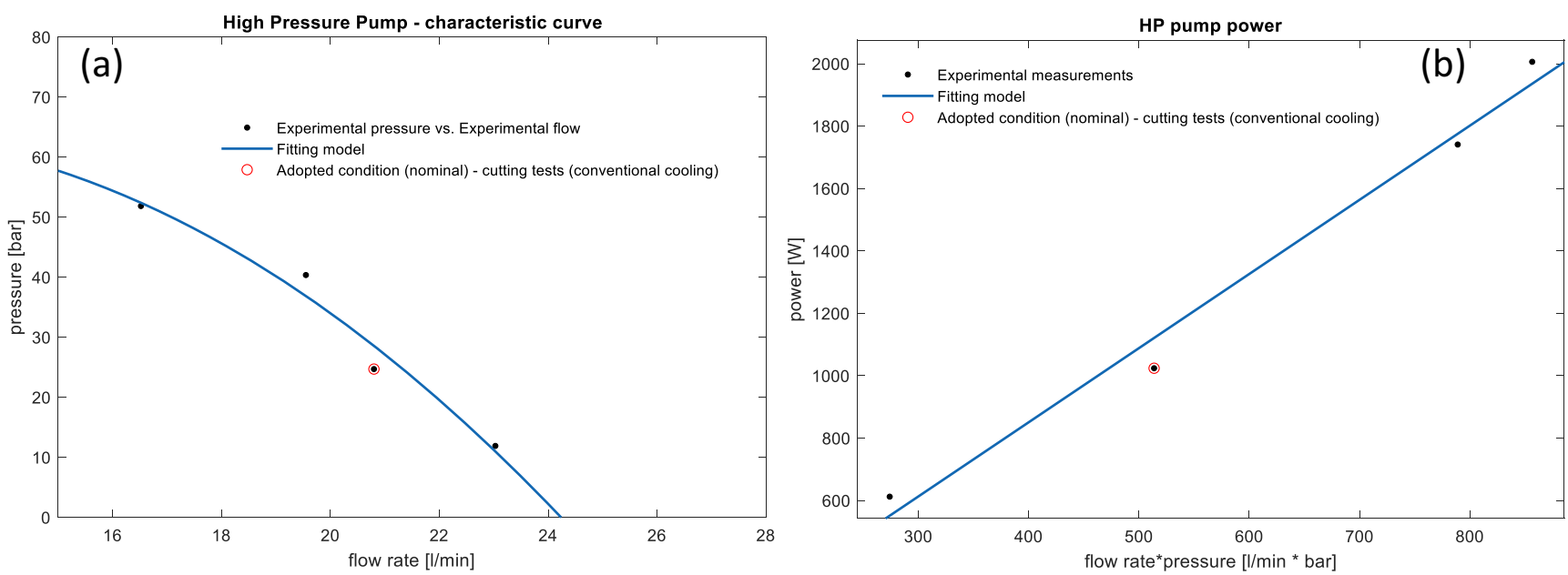

Fig. 15 Conventional cooling: (a) high-pressure (HP) pump for lubricant - characteristic curve - experimental data and identified model and (b) absorbed electrical power - experimental data and identified model

The power associated to the CED linked to the production of lubricant depends on $V_{\text {lub }}$ that is the lubricant used in a year. More specifically, Eq. 51 can be written:

$V_{\text {lub }}=V_{\mathrm{H}_{2} \mathrm{O}}+V_{\mathrm{H}_{2} \mathrm{O}} \cdot$ conc

where $V_{\mathrm{H}_{2} \mathrm{O}}$ is the year consumption of water and conc is the concentration of oil in the lubricant.

Therefore, Eq. 52 can be written:

$$
\begin{aligned}
& P_{\mathrm{CED}_{\text {conv }}}\left(V_{\text {lub }}\right) \\
& =\frac{\left(V_{\mathrm{H}_{2} \mathrm{O}} \cdot \rho_{\mathrm{H}_{2} \mathrm{O}} \cdot \mathrm{CED}_{\mathrm{H}_{2} \mathrm{O}}+V_{\text {oil }} \cdot \rho_{\text {oil }} \cdot \mathrm{CED}_{\text {oil }}\right)}{N_{\text {days } / \text { year }} \cdot N_{\text {hours } / \text { day }} \cdot 3600}
\end{aligned}
$$

And both $N_{\text {days/year }}$ and $N_{\text {hours/day }}$ were used to get the right units. For this research, the following values were adopted: $V_{\mathrm{H}_{2} \mathrm{O}}=7000 \mathrm{l} /$ year and conc $=12 \%$. The annual consumption of water was experimentally measured on a machine centre (similar to the one adopted for the experimentation) used in a real shop-floor. The procedure adopted in the company is to periodically add water and oil to the machine to keep the concentration constant. The used oil concentration value is typical for conventional Ti6Al4V milling. The CED values both for water $\left(\mathrm{CED}_{\mathrm{H}_{2} \mathrm{O}}=0.00355 \mathrm{MJ} / \mathrm{kg}\right)$ and synthetic oil $\left(\mathrm{CED}_{\text {oil }}=31.74 \mathrm{MJ} / \mathrm{kg}\right)$ were found in the database [82]. $\rho_{\text {oil }}=0.82 \mathrm{~kg} / \mathrm{l}$ is the oil density.

Table 6 High-pressure pump - identified model parameters

\begin{tabular}{ll}
\hline Parameter & Value \\
\hline$\widehat{a}_{2}\left[\mathrm{bar} /(1 / \mathrm{min})^{2}\right]$ & -0.355 \\
$\widehat{a}_{1}[\mathrm{bar} /(1 / \mathrm{min})]$ & 7.68 \\
$\widehat{a}_{0}[\mathrm{bar}]$ & 22.43 \\
$\widehat{b}_{1}[\mathrm{~W} /(\mathrm{bar} \cdot 1 / \mathrm{min})]$ & 2.38 \\
$\widehat{b}_{0}[\mathrm{~W}]$ & -100 \\
\hline
\end{tabular}

Since $P_{\text {feed }}$-sucteryo $=0$, the cryogenic-dry pair can be evaluated through Eq. 53.

$$
\begin{aligned}
& \Delta P_{\text {global }_{\text {cyo-dy }}}[\%]\left(\dot{m}_{L N}, \overline{v_{c}}, a_{e} / D, f_{z}\right) \\
& =100 \frac{\left(P_{\text {CED }_{\text {cyo }}}\left(\dot{m}_{L N}\right)+P_{\text {spindle }_{\text {cryo }}}\left(\overline{v_{c}}, a_{e} / D, f_{z}\right)\right)-\left(P_{\text {spindle dry }}\left(\overline{v_{c}}, a_{e} / D, f_{z}\right)\right)}{P_{\text {spindle }_{\text {dry }}}\left(\overline{v_{c}}, a_{e} / D, f_{z}\right)}
\end{aligned}
$$

The power associated to the CED for the production of liquid nitrogen $P_{\mathrm{CED}_{\text {cyo }}}$ depends on the liquid nitrogen mass flow rate $\dot{m}_{L N}$.

$P_{\mathrm{CED}_{\text {cryo }}}$ can be computed as follows:

$\frac{P_{\mathrm{CED}_{\text {cyo }}}=P_{\mathrm{CED}_{\mathrm{cyy}}}\left(\dot{m}_{L N}\right)=\dot{m}_{L N} \cdot \mathrm{CED}_{L N}}{3600}$

As anticipated, $\overline{\dot{m}_{L N}}=45 \mathrm{~kg} / \mathrm{h}$ is the liquid nitrogen mass flow rate measured in the nominal condition of pressure (press $=3.5$ bar). The energy required for the production of the liquid nitrogen was set equal to $\mathrm{CED}_{L N}=$ 6.49 MJ [82].

It is worth noting that, according to $[35,82]$, the developed formulation does not consider the energy required for the lubricant disposal and the energy contribution 
Table 7 Suction pump model parameters

\begin{tabular}{ll}
\hline Parameter & Value \\
\hline$P_{\text {suct }}[\mathrm{W}]$ & 5500 \\
$Q_{\text {suct }}[1 / \mathrm{min}]$ & 700 \\
$V_{\text {tank }-\max }$ & 749 \\
\hline
\end{tabular}

linked to the production of the inserts that need to be substituted when worn. Indeed, it was assumed that the cutting performance, in terms of wear rate, can be considered comparable in all the analysed cases although a worse performance is expected for dry cutting. According to the literature, the comparison between conventional and cryogenic cutting in milling is often not in agreement $[26,60]$.

\section{Results and discussion}

In this section, the results of the performed power assessment as described in the previous subsections were presented. A proper validation of the proposed modelling approach was presented first (Section 3.1 and Section 3.3).

\subsection{Model validation}

The model validation was carried out comparing both the estimated cutting power and spindle power (Section 2.2.1) with the associated experimental values (see Fig. 16). The model validation was performed considering the following cutting condition: $v_{c}=50 \mathrm{~m} / \mathrm{min}, f_{z}=0.2 \mathrm{~mm} / \mathrm{tooth}, a_{e}=$ $5 \mathrm{~mm}$ and $a_{p}=3 \mathrm{~mm}$.

For what concerns the real cutting power, it was directly derived from cutting force measurements. Since for the adopted cutting condition (radial engagement $\mathrm{a}_{\mathrm{e}}$ ) at maximum one tooth is engaged in the piece, the following expressions can be used for computing the average cutting power:

$$
\begin{aligned}
& \left\{\begin{array}{l}
F_{t i_{e x}}(t) \\
F_{r i_{e x}}(t)
\end{array}\right\}=\boldsymbol{R}_{i} \cdot\left\{\begin{array}{l}
F_{x}(t) \\
F_{y}(t)
\end{array}\right\} \\
& =\left[\begin{array}{cc}
-\sin \varphi_{i}(t) & \cos \varphi_{i}(t) \\
-\cos \varphi_{i}(t) & -\sin \varphi_{i}(t)
\end{array}\right] \cdot\left\{\begin{array}{l}
F_{x}(t) \\
F_{\mathrm{y}}(t)
\end{array}\right\}
\end{aligned}
$$

where the $F_{x}$ and $F_{y}$ are the measured experimental forces along $X$ and $Y$ and $\boldsymbol{R}_{\boldsymbol{i}}$ is a rotation matrix that allows computing respectively the tangential $F_{t i_{e x}}$ and radial $F_{r i_{e x}}$ components (Eq. 55). Thus, the experimental cutting power $P_{\text {cut }}$, as a function of time, can be estimated using Eq. 56:

$P_{\text {cut }}(t)=F_{t i_{e x}}(t) \cdot v_{c} / 60$

And the average value $\overline{\overline{P_{c u t e x}}}$ can be computed considering a defined number of tool rotations $(q=30)$.

$\overline{\overline{P_{\text {cutex }}}}=\frac{1}{q \cdot T} \int_{0}^{q \cdot T} P_{\text {cutex }_{e x}}(t) \cdot d \mathrm{t}$

Moreover, even the confidence intervals CI $\pm 3 \sigma$ of the experimental cutting power were estimated for all the experimented cooling conditions (Eq. 58):

$\sigma_{P_{\text {cutex }_{\text {ex }}}}=\sqrt{\frac{1}{q-1} \sum_{p=1}^{q}\left|\overline{P_{\text {cutex }_{\text {ex }}}}-\overline{\overline{P_{\text {cutex }}}}\right|^{2}}$

where $\overline{P_{\text {cutexp }}}$ is the average cutting power in the $p^{\text {th }}$ tool revolution.

It can be observed that the experimental cutting power (Eqs. 55, 56 and 57) matches the computed one through Eqs. 9, 10 and 11 and the identified cutting coefficients
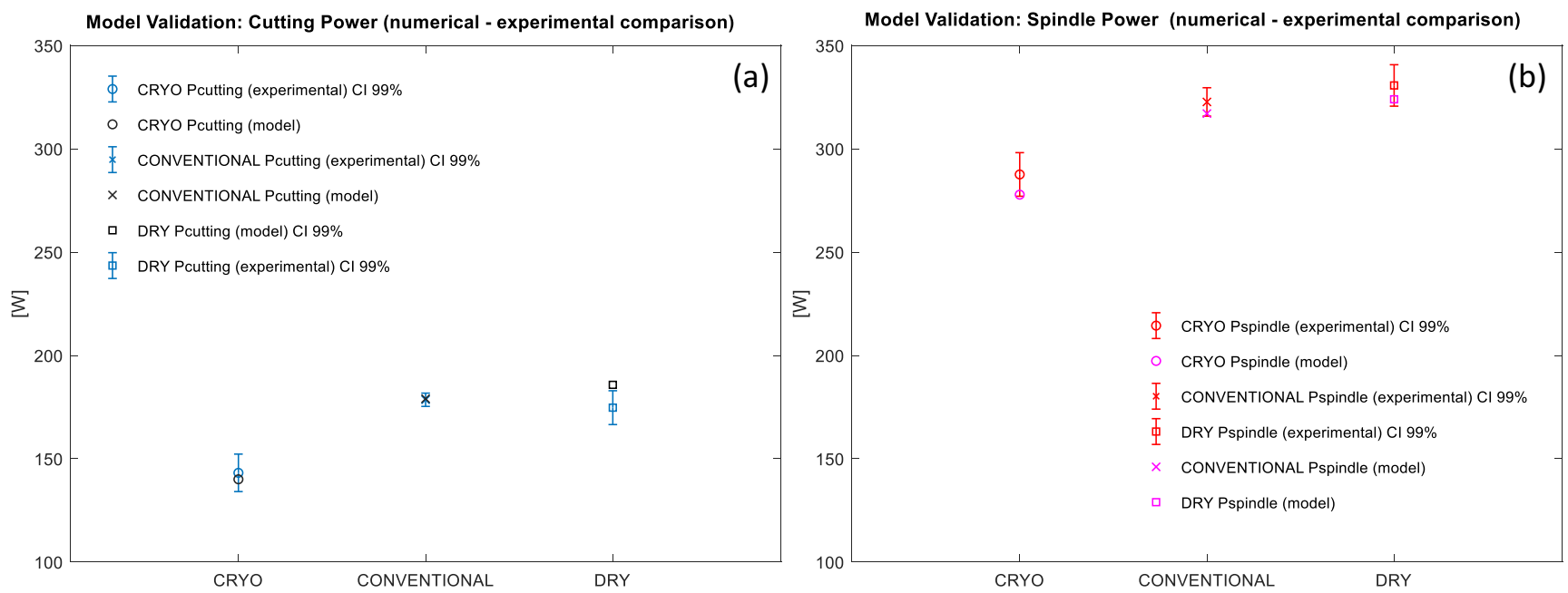

Fig. 16 Cutting power (a) and spindle power (b) - different cooling lubricating CL approaches - experimental and numerical model comparison (validation point, $v_{c}=50 \mathrm{~m} / \mathrm{min}, f_{z}=0.2 \mathrm{~mm} /$ tooth, $a_{e}=5 \mathrm{~mm}, a_{p}=3 \mathrm{~mm}$ ) 

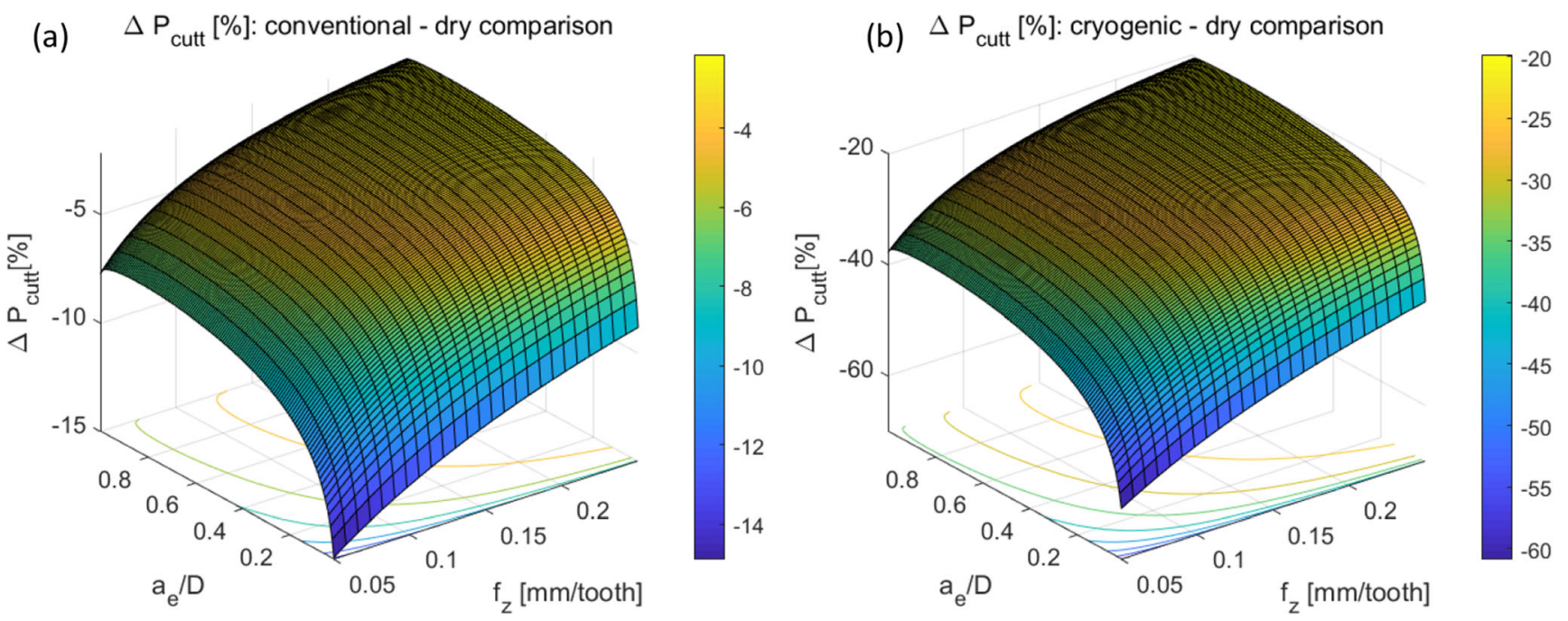

Fig. 17 Cutting power assessment: (a) conventional-dry comparison and (b) cryogenic-dry comparison

(Table 4). The best matching can be observed for conventional cooling. The maximum error is about $6 \%$ and it was observed for dry cutting.

Regarding the spindle power, in Fig. 16b, the analytically estimated value (Eq. 29) was compared with the measured one. The spindle power measurements were performed using the power meter depicted in Fig. 12. The comparison was done both for dry cutting, cryogenic and conventional cooling. Even in this case, the maximum error is rather limited (about $4 \%$ for the cryogenic cooling). According to the observed results, the model can be considered suitable for the purpose of the proposed analysis.

\subsection{Cutting power assessment results}

Since the cryogenic cooling exhibited a strong tendency in reducing the cutting forces, a structured analysis of the associated potentiality in terms of cutting power needs to be carried out. For this purpose, the analytical formulation devised and presented in Section 2.1 was exploited. Indeed, the cutting power assessment was performed exploiting Eq. 15 and Eq. 14. The identified cutting coefficients (Table 4) were used, while $f_{z}$ was varied in a range $0.05-0.2 \mathrm{~mm} /$ tooth, and the dimensionless parameter $\left(a_{e} / D\right)$ was assumed in the $0.2-1$ range. According to the devised formulation, the assessment of cryogenic and conventional cooling was carried out with respect to dry cutting that represents the reference case in terms of environmental sustainability.

As can be easily observed in Fig. 17b, the expected cutting power saving (with respect to dry cutting) ranges from $-20 \%$ to more negative values depending on the selected cutting parameters (up to $-60 \%$ for low radial immersions and lower feeds (finishing operations)). When the tool is fully engaged on the workpiece and the feed is set to its maximum value $(0.25 \mathrm{~mm} /$ tooth$)$, the cutting power saving results in its minimum value. This is due the fact that in that condition, the tangential cutting force is dominated by the shear contribution (linked to $K_{t c}$ ) (see Eq. 14). On the contrary, when the feed $f_{z}$ and the radial depth of cut $a_{e}$ are both reduced, the friction contribution (linked to $K_{t e}$ ) plays the main role, drastically decreasing the cutting power in comparison to dry cutting. For what concerns the conventional-dry comparison, Fig. 17 a shows that for rough milling, the cutting power is comparable, while for finishing operations (lower values of $f_{z}$ and $a_{e}$ $D$ ), the conventional cutting seems less energy demanding than dry cutting mainly due to a better lubrication effectiveness, even explained by a lower $K_{t e}$. Focusing on power
Table 8 Spindle power assessment - sensitive analysis as a function of cutting speed

\begin{tabular}{llll}
\hline$\Delta P_{\text {spindle }}[\%]$ & $\begin{array}{c}\Delta P_{\text {spindle }}[\%]-\text { lower } \\
\text { bound }\end{array}$ & $\begin{array}{l}\Delta P_{\text {spindle }}[\%]-\text { upper } \\
\text { bound }\end{array}$ & $C L$ comparison \\
\hline Nominal cutting speed $\overline{v_{c}}$ & -5.1 & -0.84 & Conventional-dry \\
$v_{c \text { low }}$ & -5.8 & -1.3 & Conventional-dry \\
$v_{c \text { high }}$ & -4.5 & -0.63 & Conventional-dry \\
Nominal cutting speed $\overline{v_{c}}$ & -24.9 & -3.6 & Cryo-dry \\
$v_{c \text { low }}$ & -28.5 & -5.5 & Cryo-dry \\
$v_{c \text { high }}$ & -22.6 & -2.7 & Cryo-dry \\
\hline
\end{tabular}



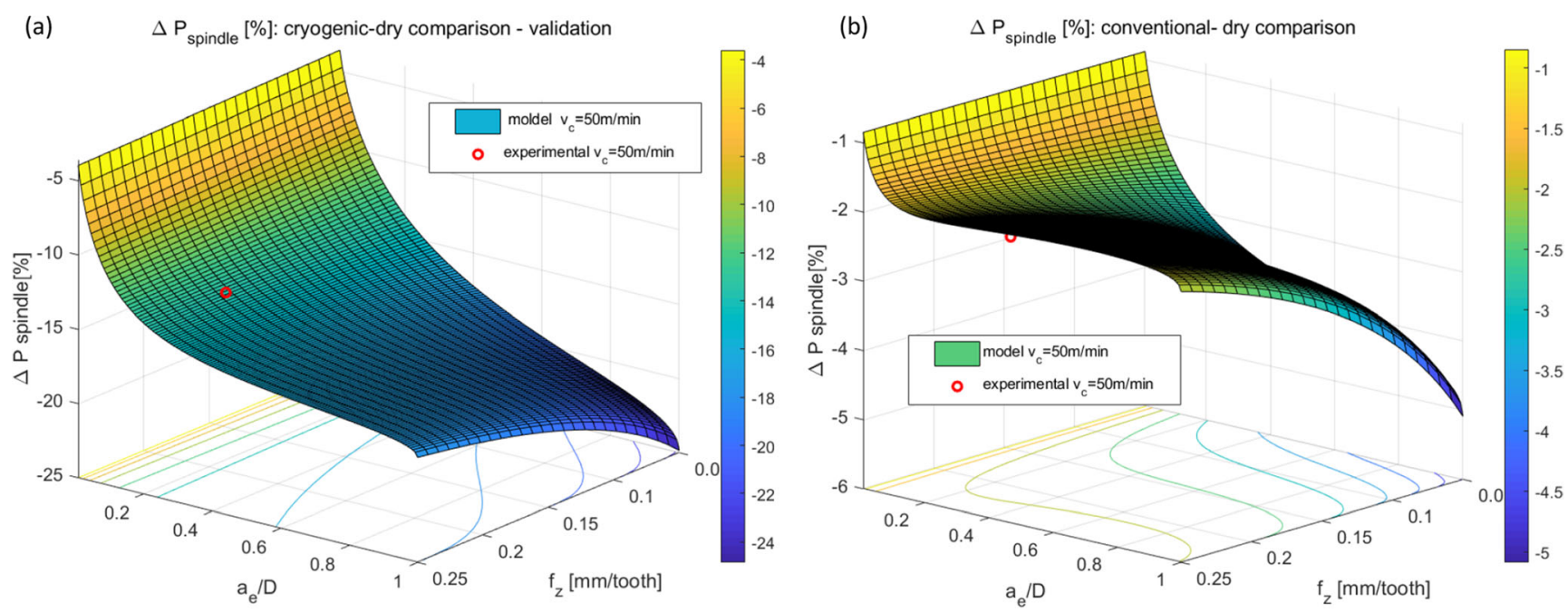

Fig. 18 Spindle power assessment and model validation: (a) conventional-dry comparison and (b) cryogenic-dry comparison

associated to cutting, cryogenic cutting seems the most sustainable cooling lubricant solution.

\subsection{Power assessment results at the spindle level and model validation}

Similarly, in this section, the assessment was performed at a higher level. The spindle power was considered for this purpose. According to Eq. 30 and Eq. 31, the conventional-dry spindle power comparison (Fig. 18a) and the cryogenic-dry pair (Fig. 18b) were reported. Moreover, as a confirmation of the adequacy of adopted modelling approach, the corresponding measured quantities (also reported in Section 3.1) were put into evidence in Fig. 18. As summarized in Table 8, the lower and upper bound values for $\Delta P_{\text {spindle }}[\%]$ were reported for both the comparisons, considering the nominal cutting speed that in this case was set $\bar{v}_{c}=50 \mathrm{~m} / \mathrm{min}$. A sensitive analysis considering different values of cutting velocity was also performed. More specifically, the following values were considered: $v_{c}$ low $=30 \mathrm{~m} / \mathrm{min}$ and $v_{c}$ high $=70 \mathrm{~m} / \mathrm{min}$. It can be observed that for roughing operations (high radial immersions and high feeds), cryogenic cooling can assure savings up to $18 \%\left(\right.$ at $\left.\bar{v}_{c}\right)$ with respect to the power absorbed by the spindle in dry conditions. Higher percentage savings (up to 25\%) occur when the feed is further decreased. The observed power savings are even more relevant if a lower cutting velocity is considered $v_{c}$ low (Table 8).

Conventional cutting showed that spindle power consumption $P_{\text {spindle }}$ is similar to the corresponding one observed in dry cutting. Indeed, only slight differences can be observed (less than $-6 \%$ ). If we consider this perspective, cryogenic cutting remains particularly convenient especially for operations in which the tool is rather engaged in the workpiece. This matches the typical needs of soe

\section{$\Delta \mathrm{P}_{\text {feed }}[\%]$ : conventional - dry comparison}

(a)

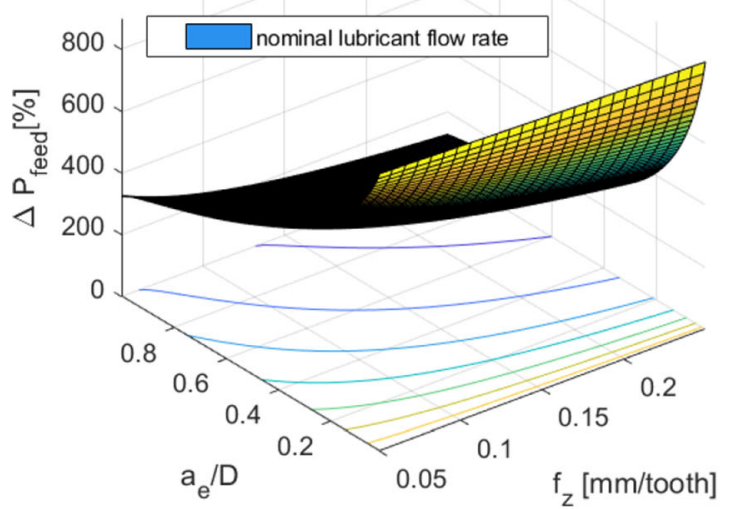

$\Delta \mathrm{P}_{\text {feed-suct }}[\%]$ : conventional - dry comparison

(b)

700

600

500

$400 \stackrel{1}{\circ}$

300

200

b)

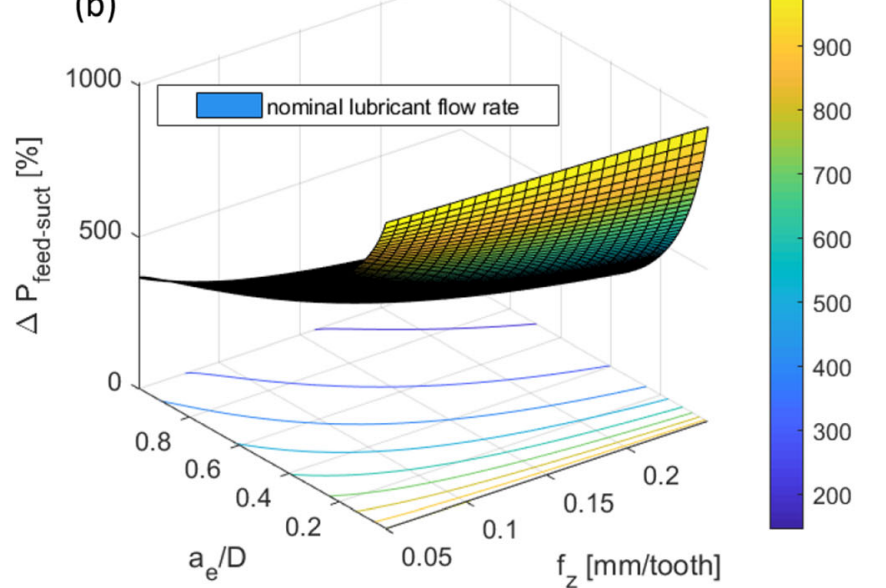

Fig. 19 Power at the machine level (conventional-dry comparison) - (a) high-pressure pump and (b) high-pressure and suction pumps (both considering the nominal flow rate $\overline{Q_{\text {lub }}}$ and the nominal $\overline{v_{c}}$ ) 
Table 9 Conventional-dry comparison - power assessment at the machine level (high-pressure pump)

\begin{tabular}{llll}
\hline$\Delta P_{\text {feed }}[\%]$ & $\begin{array}{l}\Delta P_{\text {feed }}[\%]-\text { lower } \\
\text { bound }\end{array}$ & $\begin{array}{l}\Delta P_{\text {feed }}[\%]-\text { upper } \\
\text { bound }\end{array}$ & $C L$ comparison \\
\hline Nominal flow rate $\overline{Q_{\text {lub }}}$ & 129 & 878 & Conventional-dry \\
$1.15 \cdot \overline{Q_{\text {lub }}}$ & 5 & 47 & Conventional-dry \\
$0.85 \cdot \overline{Q_{\text {lub }}}$ & 186 & 1291 & Conventional-dry \\
\hline
\end{tabular}

applications where, for instance in aerospace industry, up to $90 \%$ of the material is removed from the blank by machining operations.

For finishing operations, the energy savings with respect to conventional cooling are rather limited (less than 5\%).

\subsection{Power assessment results at the machine level}

In this section, the focused was shifted to the machine. This means that the machine tool was considered the system boundary. From this perspective, the power assessment was carried out considering even the feed system (Eq. 44 and Eq. 46). More in details, Eq. 44 takes into consideration the power contribution due to high-pressure pump, while Eq. 46 considers in addition the power associated to the suctioning pump. The corresponding analyses were reported respectively in Fig. 19 $\mathrm{a}$ and $\mathrm{b}$ where the nominal $\overline{Q_{\mathrm{lub}}}$ and the nominal $\overline{\mathrm{v}_{\mathrm{c}}}$ were set.

Since for cryogenic cooling no additional power contributions need to be taken into account at the machine level, the analysis performed in the previous section still remains valid (Fig. 18b). A sensitive analysis as a function of the $Q_{\text {lub }}$ was also carried out. Deviations from the nominal value $\overline{Q_{\text {lub }}}$ (experimentally measured during the cutting test with the adopted tool) of $\pm 15 \%$ were considered.

It can be observed that the high-pressure pump plays a relevant role (it absorbed about $1312 \mathrm{~W}$ in the nominal condition), while the suctioning pump power is quite limited with an average contribution of about $163 \mathrm{~W}$. Even for roughing operations, the power percentage increment with respect to dry cutting is considerable $(145 \%)$. Moreover, in both the cases (Tables 9,10$)$, reducing the $Q_{\text {lub }}$ makes the conventional cutting even more power demanding (200\% for roughing operations and $1387 \%$ for finishing operations).
It can be concluded that if we consider the perspective of a manufacturing plant, without doubts, the choice of using cryogenic cutting as a cooling lubricating solution allows saving a lot of energy with respect to conventional cutting (close to 3 times for roughing machining and more than 11 times for finishing operations). This analysis and the analysed results are extremely relevant for manufacturing companies that deal with titanium alloys machining.

\subsection{Primary power assessment results}

According to Section 2.4, the analysis was shifted to a global perspective. Indeed, the CED energy for producing lubricant and liquid nitrogen was also considered. More in details, Eq. 50 and Eq. 53 were used to plot the curves reported in Fig. 20.

Specifically, the nominal conditions for what concerns the consumption of lubricant $\overline{V_{\text {lub }}}$ (Fig. 20a) and the liquid nitrogen $\overline{m_{L N}}$ flow rate (Fig. 20b) were considered. In addition, the nominal conditions for $\overline{Q_{\text {lub }}}$ and $\overline{v_{c}}$.were also set. The analysis shows that due to a high consumption of liquid nitrogen that evaporates as soon as it cools the cutting region, the involved global power is much higher than dry cutting (about 19 times greater than conventional cutting for finishing and up to 16 times in case of rough milling).

The sensitive analysis shows (Table 11) that the achieved results seem less detrimental than the ones reported in [35, 61]. Even [61], that carried out an analysis considering the data gathered in literature for estimating the primary energy, found that cryogenic cooling averagely demands 39 time the energy
Table 10 Conventional-dry comparison - power assessment at the machine level (high-pressure and suctioning pump)

\begin{tabular}{clll}
\hline$\Delta P_{\text {feed-suct }}[\%]$ & $\begin{array}{l}\Delta P_{\text {feed-suct }}[\%]-\text { lower } \\
\text { bound }\end{array}$ & $\begin{array}{l}\Delta P_{\text {feed-suct }}[\%]-\text { upper } \\
\text { bound }\end{array}$ & $C L$ comparison \\
\hline Nominal flow rate $\overline{Q_{\text {lub }}}$ & 145 & 1011 & Conventional-dry \\
$1.15 \cdot \overline{Q_{\text {lub }}}$ & 24 & 176 & Conventional-dry \\
$0.85 \cdot \overline{Q_{\text {lub }}}$ & 200 & 1387 & Conventional-dry \\
\hline
\end{tabular}


Table 11 Global power assessment (different CL technologies) $\Delta \mathrm{P}_{\text {global }}[\%]-$ sensitive analysis

\begin{tabular}{llll}
\hline$\Delta P_{\text {global }}[\%]$ & $\begin{array}{l}\Delta P_{\text {global }}[\%]-\text { lower } \\
\text { bound }\end{array}$ & $\begin{array}{c}\Delta P_{\text {global }}[\%]-\text { upper } \\
\text { bound }\end{array}$ & $C L$ comparison \\
\hline Nominal lubricant consumption $\overline{V_{\text {lub }}}$ & 419 & 2897 & Conventional-dry \\
$1.15 \cdot \overline{V_{\text {lub }}}$ & 460 & 3180 & Conventional-dry \\
$0.85 \cdot \overline{V_{\text {lub }}}$ & 378 & 2614 & Conventional-dry \\
Nominal LN flow rate $\overline{m_{L N}}$ & 8069 & 55,630 & Cryo-dry \\
$0.85 \cdot \overline{\dot{m}_{L N}}$ & 6856 & 47,290 & Cryo-dry \\
$1.15 \cdot \overline{\dot{m}_{L N}}$ & 9282 & 63,980 & Cryo-dry \\
\hline
\end{tabular}

requested by conventional cutting. Most likely this is due to the developed set-up that feeds the liquid nitrogen through the tool nozzles instead of using flood.

Since in conventional cutting the lubricant is continuously reused and only periodically refilled or substituted, the associated primary power is lower Thus, changing the perspective to a higher level makes the considerations outlined in Section 3.4 completely reviewed. It is important to observe that this analysis took into consideration the primary power consumption, but it was not focused on other environmental aspects like global warming, acidification, water usage and solid wasted [35] or features linked to the quality of the processed parts [36, 37].

The performed analyses (considering respectively

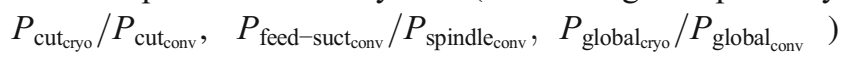
bring to the results summarized in Fig. 21.

\section{Conclusions}

In this paper, a comprehensive energy assessment of both cryogenic (LN2) cooling and conventional cooling was

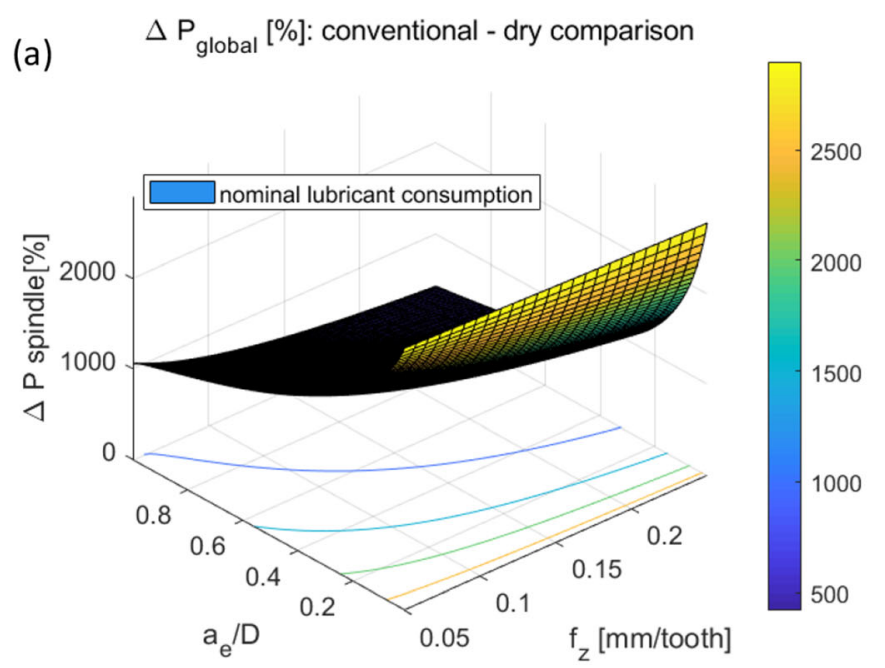

carried out with respect to dry cutting. Ti6A14V milling was considered the reference application.

- The energy assessment was carried out at different levels. More specifically, the power involved in machining, the power absorbed by spindle, the power linked to the machine tool system and the primary power were considered.

- At each level, a proper energy model was developed to analyse the effect of the main cutting and process parameters (radial depth of cut, feed, cutting velocity, lubricant flow rate, LN2 flow rate).

- At the process level, cryogenic cooling makes Ti6Al4V cutting less energy demanding than dry cutting and conventional cooling. The results were explained through a mechanistic cutting model. Basically, LN2 lowers the friction between the tool and the workpiece.

- Cryogenic cooling assures energy saving even if the spindle losses were considered in the analysis.

- Relevant savings were also observed if the machine tool energy consumption was analysed. Indeed, the power absorbed by the machine auxiliaries makes conventional cutting from 3 to 11 times (depending on the cutting parameters) more energy demanding than

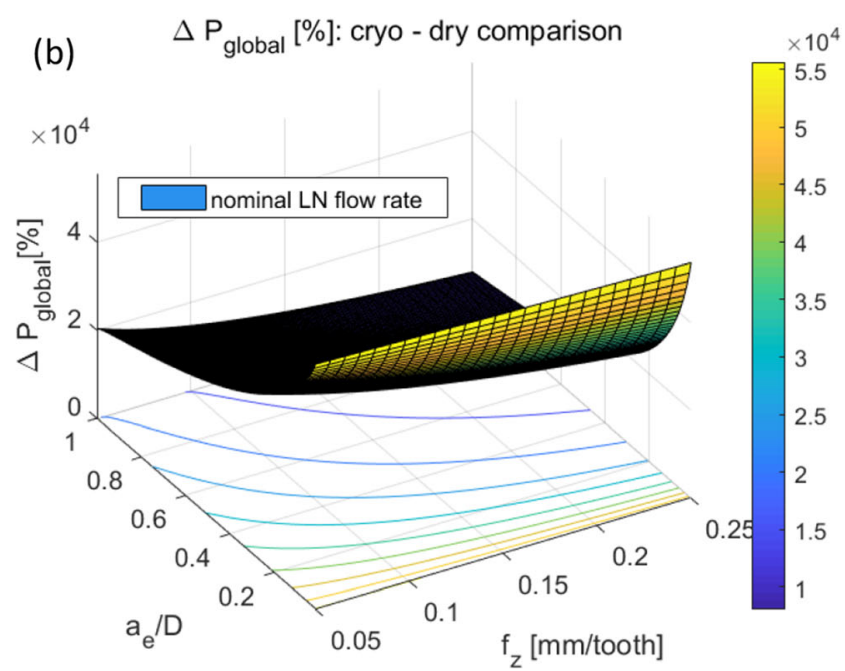

Fig. 20 Global power assessment: (a) conventional-dry comparison (nominal conditions $\overline{V_{\text {lub }}}, \overline{Q_{\text {lub }}}, \overline{v_{c}}$ ) and (b) cryogenic-dry comparison (nominal conditions $\left(\overline{\dot{m}_{L N}}, \overline{v_{c}}\right)$ 

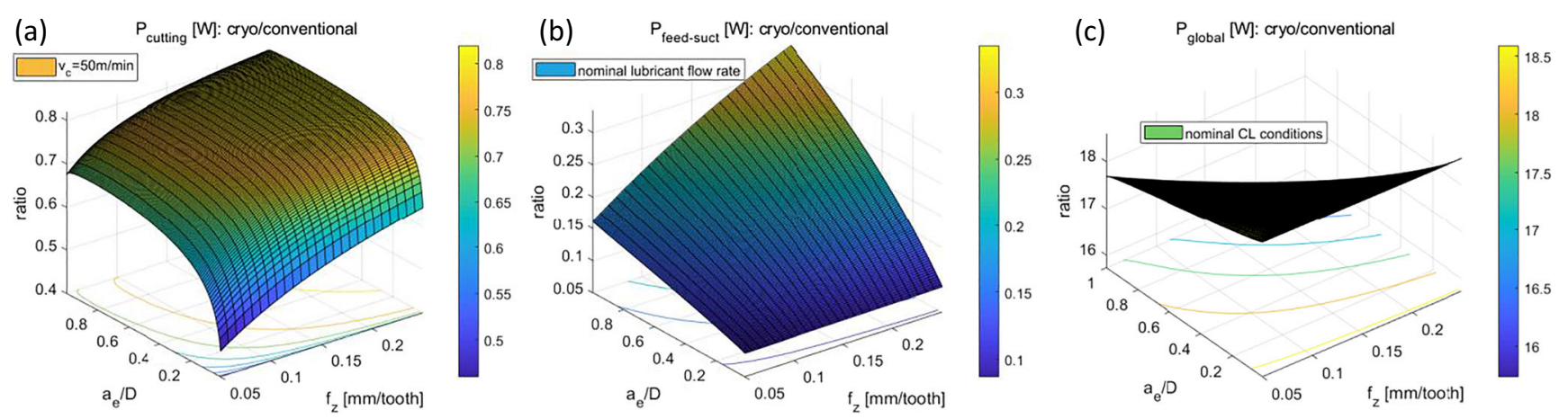

Fig. 21 cryogenic cooling - conventional cooling comparison at different levels: (a) cutting power (b) machine level (c) primary power

cryogenic cutting. This result is extremely interesting for companies that process advanced material like HRA.

- Primary energy. Since the liquefaction of nitrogen is an energy demanding process, the overall requested energy in cryogenic cutting is close to be from 16 to 19 times higher than in conventional cutting.

- In order to make cryogenic LN2 even more environmental compliant, research efforts should be addressed to improve the efficiency of the feeding system that should assure a stable flow even with low LN2 rates. A more localized action of the jets needs to be pursued in order to avoid any waste of nitrogen and to enhance the cutting performance in terms of tool life and MRR.

Acknowledgements The project involves an important Italian machine tool manufacturer, Jobs Spa (FFG group). The authors would like to thank all the company staff (Eng. Solari) that collaborated to the project development. Moreover, the authors would like to thank the SIAD company for the LN2 delivery and for the collaboration on the cryogenic plant enhancement and Eng. Valerio Mussi for his support during the experimental cutting tests.

Authors' contributions Paolo Albertelli conceived the research, performed the tests, developed and validated the models and wrote the paper. Michele Monno carried out the proofreading

Funding Open Access funding provided by Politecnico di Milano. This work was supported by the Ministero dello Sviluppo Economico (Nuovo processo di asportazione di truciolo supportato da fluido criogenico per materiali aeronautici di difficile lavorabilità: incremento della produttività, riduzione dei costi ed eliminazione degli oli da taglio).

Data availability Not applicable.

\section{Compliance with ethical standards}

Conflict of interest The authors declare that they have no competing interests.

Code availability Not applicable.

Open Access This article is licensed under a Creative Commons Attribution 4.0 International License, which permits use, sharing, adaptation, distribution and reproduction in any medium or format, as long as you give appropriate credit to the original author(s) and the source, provide a link to the Creative Commons licence, and indicate if changes were made. The images or other third party material in this article are included in the article's Creative Commons licence, unless indicated otherwise in a credit line to the material. If material is not included in the article's Creative Commons licence and your intended use is not permitted by statutory regulation or exceeds the permitted use, you will need to obtain permission directly from the copyright holder. To view a copy of this licence, visit http://creativecommons.org/licenses/by/4.0/.

\section{References}

1. Veiga C, Davim JP, Loureiro AJR (2013) Review on machinability of titanium alloys: the process perspective. Adv Mater Sci 34:148-164

2. Sharma VS, Dogra M, Suri NM (2009) Cooling techniques for improved productivity in turning. Int J Mach Tools Manuf 49: 435-453

3. Brinksmeier E, Meyer D, Huesmann-Cordes AG, Herrmann C (2015) Metalworking fluids - mechanisms and performance. CIRP Ann Manuf Technol 64:605-628. https://doi.org/10.1016/j. cirp.2015.05.003

4. Shokrani A, Dhokia V, Newman ST (2012) Environmentally conscious machining of difficult-to-machine materials with regard to cutting fluids. Int J Mach Tools Manuf 57:83-101. https://doi.org/ 10.1016/J.IJMACHTOOLS.2012.02.002

5. Sharif MN, Pervaiz S, Deiab I (2017) Potential of alternative lubrication strategies for metal cutting processes: a review. Int J Adv Manuf Technol 89:2447-2479. https://doi.org/10.1007/s00170016-9298-5

6. Calvert GM, Ward E, Schnorr TM, Fine LJ (1998) Cancer risks among workers exposed to metalworking fluids: a systematic review. Am J Ind Med 33:282-292

7. Malloy EJ, Miller KL, Eisen EA (2007) Rectal cancer and exposure to metalworking fluids in the automobile manufacturing industry. Occup Environ Med 64:244-249. https://doi.org/10.1136/oem. 2006.027300

8. Adler DP, Hii WW-S, Michalek DJ, Sutherland JW (2006) Examining the role of cutting fluids in machining and efforts to address associated in machining to address associated environmental/health concerns. Mach Sci Technol 10:23-58. https://doi.org/10.1080/10910340500534282

9. Khan AM, He N, Jamil M, Raza SM (2021) Energy characterization and energy-saving strategies in sustainable machining processes: a state-of-the-art review. J Prod Syst Manuf Sci 2:26-49

10. Deiab I, Raza SW, Pervaiz S (2014) Analysis of lubrication strategies for sustainable machining during turning of Titanium Ti-6Al- 
4V alloy. Procedia CIRP 17:766-771. https://doi.org/10.1016/j. procir.2014.01.112

11. Gupta K, Laubscher RF (2017) Sustainable machining of titanium alloys: a critical review. Proc Inst Mech Eng B J Eng Manuf 231: 2543-2560. https://doi.org/10.1177/0954405416634278

12. Pervaiz S, Anwar S, Qureshi I, Ahmed N (2019) Recent advances in the machining of titanium alloys using minimum quantity lubrication (MQL) based techniques. Int J Precis Eng Manuf Green Technol 6:133-145

13. Singh R, Dureja JS, Dogra M et al (2020) Evaluating the sustainability pillars of energy and environment considering carbon emissions under machining ofTi-3Al-2.5 V. Sustainable Energy Technol Assess 42:100806. https://doi.org/10.1016/j.seta.2020. 100806

14. Khan AM, Jamil M, Mia M, He N, Zhao W, Gong L (2020) Sustainability-based performance evaluation of hybrid nanofluid assisted machining: sustainability assessment of hybrid nanofluid assisted machining. J Clean Prod 257:120541. https://doi.org/10. 1016/j.jclepro.2020.120541

15. Khan AM, Gupta MK, Hegab H, Jamil M, Mia M, He N, Song Q, Liu Z, Pruncu CI (2020) Energy-based cost integrated modelling and sustainability assessment of Al-GnP hybrid nanofluid assisted turning of AISI52100 steel. J Clean Prod 257:120502. https://doi. org/10.1016/j.jclepro.2020.120502

16. Banerjee N, Sharma A (2018) A comprehensive assessment of minimum quantity lubrication machining from quality, production, and sustainability perspectives. Sustain Mater Technol 17:e00070. https://doi.org/10.1016/j.susmat.2018.e00070

17. Pereira $\mathrm{O}$, Català $\mathrm{P}$, Rodríguez $\mathrm{A}$, Ostra $\mathrm{T}$, Vivancos $\mathrm{J}$, Rivero $\mathrm{A}$, López-de-Lacalle LN (2015) The use of hybrid CO $2+$ MQL in machining operations. Procedia Eng 132:492-499. https://doi.org/ 10.1016/j.proeng.2015.12.524

18. Pereira O, Rodríguez A, Ayesta I et al (2016) A cryo lubri-coolant approach for finish milling of aeronautical hard-to-cut materials. Int J Mechatron Manuf Syst 9:370-384

19. Pereira O, Rodríguez A, Barreiro J, Fernández-Abia AI, de Lacalle LNL (2017) Nozzle design for combined use of MQL and cryogenic gas in machining. Int J Precis Eng Manuf Green Technol 4:8795. https://doi.org/10.1007/s40684-017-0012-3

20. Grguraš D, Sterle L, Krajnik P, Pušavec F (2019) A novel cryogenic machining concept based on a lubricated liquid carbon dioxide. Int J Mach Tools Manuf:145. https://doi.org/10.1016/j.ijmachtools. 2019.103456

21. Bergs T, Pusavec F, Koch M et al (2019) Investigation of the solubility of liquid $\mathrm{CO} 2$ and liquid oil to realize an internal single channel supply in milling of Ti6Al4V. Procedia Manuf 33:200207. https://doi.org/10.1016/j.promfg.2019.04.024

22. Supekar SD, Clarens AF, Stephenson DA, Skerlos SJ (2012) Performance of supercritical carbon dioxide sprays as coolants and lubricants in representative metalworking operations. J Mater Process Technol 212:2652-2658. https://doi.org/10.1016/j. jmatprotec.2012.07.020

23. Pereira O, Rodríguez A, Fernández-Abia AI, Barreiro J, López de Lacalle LN (2016) Cryogenic and minimum quantity lubrication for an eco-efficiency turning of AISI 304. J Clean Prod 139:440-449. https://doi.org/10.1016/j.jclepro.2016.08.030

24. Pereira O, Urbikain G, Rodríguez A, Fernández-Valdivielso A, Calleja A, Ayesta I, de Lacalle LNL (2017) Internal cryolubrication approach for Inconel 718 milling. Procedia Manuf 13:89-93. https://doi.org/10.1016/J.PROMFG.2017.09.013

25. Pereira O, Celaya A, Urbikaín G, Rodríguez A, FernándezValdivielso A, Lacalle LNL (2020) CO2 cryogenic milling of
Inconel 718: cutting forces and tool wear. J Mater Res Technol 9: 8459-8468. https://doi.org/10.1016/j.jmrt.2020.05.118

26. Tapoglou N, Aceves MI, Cook I, Taylor CM (2017) Investigation of the influence of $\mathrm{CO} 2$ cryogenic coolant application on tool wear. Procedia CIRP 63:745-749. https://doi.org/10.1016/j.procir.2017. 03.351

27. Bagherzadeh A, Budak E (2018) Investigation of machinability in turning of difficult-to-cut materials using a new cryogenic cooling approach. Tribol Int 119:510-520. https://doi.org/10.1016/j. triboint.2017.11.033

28. Shokrani A, Al-Samarrai I, Newman ST (2019) Hybrid cryogenic MQL for improving tool life in machining of Ti-6Al-4V titanium alloy. J Manuf Process 43:229-243. https://doi.org/10.1016/j. jmapro.2019.05.006

29. Damir A, Shi B, Attia MH (2019) Flow characteristics of optimized hybrid cryogenic-minimum quantity lubrication cooling in machining of aerospace materials. CIRP Ann 68:77-80. https://doi.org/10. 1016/j.cirp.2019.04.047

30. Gross D, Bigelmaier M, Meier T, Amon S, Ostrowicki N, Hanenkamp N (2019) Investigation of the influence of lubricating oils on the turning of metallic materials with cryogenic minimum quantity lubrication. Procedia CIRP 80:95-100. https://doi.org/10. 1016/j.procir.2019.01.005

31. Hanenkamp N, Amon S, Gross D (2018) Hybrid supply system for conventional and CO2/MQL-based cryogenic cooling. Procedia CIRP 77:219-222. https://doi.org/10.1016/j.procir.2018.08.293

32. Jawahir IS, Attia H, Biermann D, Duflou J, Klocke F, Meyer D, Newman ST, Pusavec F, Putz M, Rech J, Schulze V, Umbrello D (2016) Cryogenic manufacturing processes. CIRP Ann Manuf Technol 65:713-736. https://doi.org/10.1016/j.cirp.2016.06.007

33. Yildiz Y, Nalbant M (2008) A review of cryogenic cooling in machining processes. Int J Mach Tools Manuf 48:947-964. https://doi.org/10.1016/J.IJMACHTOOLS.2008.01.008

34. Shokrani A, Dhokia V, Muñoz-Escalona P, Newman ST (2013) State-of-the-art cryogenic machining and processing. Int $\mathrm{J}$ Comput Integr Manuf 26:616-648. https://doi.org/10.1080/ 0951192X.2012.749531

35. Pusavec F, Krajnik P, Kopac J (2010) Transitioning to sustainable production - Part I: application on machining technologies. J Clean Prod 18:174-184. https://doi.org/10.1016/j.jclepro.2009.08.010

36. Hardt M, Klocke F, Döbbeler B et al (2018) Experimental study on surface integrity of cryogenically machined Ti-6Al-4V alloy for biomedical devices. In: Procedia CIRP. Procedia CIRP 71:181186. https://doi.org/10.1016/j.procir.2018.05.094

37. Shokrani A, Dhokia V, Newman ST (2016) Investigation of the effects of cryogenic machining on surface integrity in $\mathrm{CNC}$ end milling of Ti-6Al-4V titanium alloy. J Manuf Process 21:172179. https://doi.org/10.1016/J.JMAPRO.2015.12.002

38. Pusavec F, Kramar D, Krajnik P, Kopac J (2010) Transitioning to sustainable production - Part II: Evaluation of sustainable machining technologies. J Clean Prod 18:1211-1221. https://doi.org/10. 1016/j.jclepro.2010.01.015

39. Paul S, Sarkar S (2019) Integration of cryogenic machining technologies in advance manufacturing systems. Royal Institute of Technology Industrial

40. Pereira O, Rodríguez A, Fernández-Valdivielso A et al (2015) Cryogenic hard turning of ASP23 steel using carbon dioxide. Procedia Eng 132:486-491. https://doi.org/10.1016/j.proeng. 2015.12.523

41. Pusavec F, Deshpande A, Yang S, M'Saoubi R, Kopac J, Dillon OW Jr, Jawahir IS (2014) Sustainable machining of high temperature nickel alloy - Inconel 718: Part 1 - Predictive performance 
models. J Clean Prod 81:255-269. https://doi.org/10.1016/j.jclepro. 2014.06.040

42. Shah P, Khanna N, Chetan (2020) Comprehensive machining analysis to establish cryogenic LN2 and LCO2 as sustainable cooling and lubrication techniques. Tribol Int 148:106314. https://doi.org/ 10.1016/j.triboint.2020.106314

43. Pušavec F, Grguraš D, Koch M, Krajnik P (2019) Cooling capability of liquid nitrogen and carbon dioxide in cryogenic milling. CIRP Ann 68:73-76. https://doi.org/10.1016/j.cirp.2019.03.016

44. Lu T, Kudaravalli R, Georgiou G (2018) Cryogenic machining through the spindle and tool for improved machining process performance and sustainability: Pt. I, System Design. Procedia Manuf 21:266-272. https://doi.org/10.1016/j.promfg.2018.02.120

45. Tahmasebi E, Albertelli P, Lucchini T, Monno M, Mussi V (2019) CFD and experimental analysis of the coolant flow in cryogenic milling. Int J Mach Tools Manuf 140:20-33. https://doi.org/10. 1016/J.IJMACHTOOLS.2019.02.003

46. Rotella G, Umbrello D (2014) Finite element modeling of microstructural changes in dry and cryogenic cutting of Ti6Al4V alloy. CIRP Ann Manuf Technol 63:69-72. https://doi.org/10.1016/j.cirp. 2014.03.074

47. Umbrello D, Micari F, Jawahir IS (2012) The effects of cryogenic cooling on surface integrity in hard machining: a comparison with dry machining. CIRP Ann Manuf Technol 61:103-106. https://doi. org/10.1016/j.cirp.2012.03.052

48. Shi B, Elsayed A, Damir A, Attia H, M'Saoubi R (2019) A hybrid modeling approach for characterization and simulation of cryogenic machining of Ti-6Al-4V alloy. J Manuf Sci Eng Trans ASME 141. https://doi.org/10.1115/1.4042307

49. Augspurger T, Koch M, Klocke F, Döbbeler B (2019) Investigation of transient temperature fields in the milling cutter under $\mathrm{CO} 2$ cooling by means of an embedded thermocouple. Procedia CIRP 79:33-38. https://doi.org/10.1016/j.procir.2019.02.007

50. Sadik MI, Isakson S, Malakizadi A, Nyborg L (2016) Influence of coolant flow rate on tool life and wear development in cryogenic and wet milling of Ti-6Al-4V. Procedia CIRP 46:91-94. https://doi. org/10.1016/j.procir.2016.02.014

51. Pittalà GM (2018) A study of the effect of $\mathrm{CO} 2$ cryogenic coolant in end milling of Ti-6Al-4V. Procedia CIRP 77:445-448. https://doi. org/10.1016/J.PROCIR.2018.08.278

52. Khanna N, Shah P, Chetan (2020) Comparative analysis of dry, flood, MQL and cryogenic $\mathrm{CO} 2$ techniques during the machining of 15-5-PH SS alloy. Tribol Int 146:106196. https://doi.org/10. 1016/j.triboint.2020.106196

53. Pusavec F, Deshpande A, Yang S, M'Saoubi R, Kopac J, Dillon OW Jr, Jawahir IS (2015) Sustainable machining of high temperature nickel alloy - Inconel 718: Part 2 - Chip breakability and optimization. J Clean Prod 87:941-952. https://doi.org/10.1016/j. jclepro.2014.10.085

54. Bordin A, Bruschi S, Ghiotti A, Bariani PF (2015) Analysis of tool wear in cryogenic machining of additive manufactured Ti6Al4V alloy. Wear 328-329:89-99. https://doi.org/10.1016/j.wear.2015. 01.030

55. Bordin A, Sartori S, Bruschi S, Ghiotti A (2017) Experimental investigation on the feasibility of dry and cryogenic machining as sustainable strategies when turning Ti6Al4V produced by additive manufacturing. J Clean Prod 142:4142-4151. https://doi.org/10. 1016/j.jclepro.2016.09.209

56. Isakson S, Sadik MI, Malakizadi A, Krajnik P (2018) Effect of cryogenic cooling and tool wear on surface integrity of turned Ti6Al-4V. Procedia CIRP 71:254-259. https://doi.org/10.1016/j. procir.2018.05.061
57. Suhaimi MA, Yang G-D, Park K-H, Hisam MJ, Sharif S, Kim DW (2018) Effect of cryogenic machining for titanium alloy based on indirect, internal and external spray system. Procedia Manuf 17: 158-165. https://doi.org/10.1016/J.PROMFG.2018.10.031

58. Damir A, Sadek A, Attia H (2018) Characterization of machinability and environmental impact of cryogenic turning of Ti-6Al-4V. Procedia CIRP 69:893-898. https://doi.org/10.1016/j.procir.2017. 11.070

59. Gupta MK, Song Q, Liu Z, Sarikaya M, Jamil M, Mia M, Kushvaha V, Singla AK, Li Z (2020) Ecological, economical and technological perspectives based sustainability assessment in hybrid-cooling assisted machining of Ti-6Al-4 V alloy. Sustain Mater Technol 26: e00218. https://doi.org/10.1016/j.susmat.2020.e00218

60. Shokrani A, Dhokia V, Newman ST (2018) Energy conscious cryogenic machining of Ti-6Al-4V titanium alloy. Proc Inst Mech Eng B J Eng Manuf 232:1690-1706. https://doi.org/10.1177/ 0954405416668923

61. Supekar SD, Graziano DJ, Skerlos SJ, Cresko JJ (2020) Comparing energy and water use of aqueous and gas-based metalworking fluids. J Ind Ecol:1-13. https://doi.org/10.1111/jiec.12992

62. Rotella G, Umbrello D (2014) CIRP annals - manufacturing technology finite element modeling of microstructural changes in dry and cryogenic cutting of Ti6Al4V alloy. CIRP Ann Manuf Technol 63:11-14. https://doi.org/10.1016/j.cirp.2014.03.074

63. Bermingham MJ, Palanisamy S, Kent D, Dargusch MS (2012) A comparison of cryogenic and high pressure emulsion cooling technologies on tool life and chip morphology in Ti-6Al-4V cutting. J Mater Process Technol 212:752-765. https://doi.org/10.1016/j. jmatprotec.2011.10.027

64. Strano M, Chiappini E, Tirelli S, Albertelli P, Monno M (2013) Comparison of Ti6Al4V machining forces and tool life for cryogenic versus conventional cooling. Proc Inst Mech Eng B J Eng Manuf 227:1403-1408. https://doi.org/10.1177/ 0954405413486635

65. Mia M, Dhar NR (2019) Influence of single and dual cryogenic jets on machinability characteristics in turning of Ti-6Al-4V. Proc Inst Mech Eng B J Eng Manuf 233:711-726. https://doi.org/10.1177/ 0954405417737581

66. Hong SY, Markus I, Jeong W (2001) New cooling approach and tool life improvement in cryogenic machining of titanium alloy Ti6Al-4V. Int J Mach Tools Manuf 41:2245-2260. https://doi.org/10. 1016/S0890-6955(01)00041-4

67. Bermingham MJ, Kirsch J, Sun S, Palanisamy S, Dargusch MS (2011) New observations on tool life, cutting forces and chip morphology in cryogenic machining Ti-6Al-4V. Int J Mach Tools Manuf 51:500-511. https://doi.org/10.1016/j.ijmachtools.2011.02.009

68. Hong SY, Ding Y, Jeong W (2001) Friction and cutting forces in cryogenic machining of Ti-6Al-4V. Int J Mach Tools Manuf 41: 2271-2285. https://doi.org/10.1016/S0890-6955(01)00029-3

69. Reddy PP, Ghosh A (2014) Effect of cryogenic cooling on spindle power and G-ratio in grinding of hardened bearing steel. Procedia Mater Sci 5:2622-2628. https://doi.org/10.1016/j.mspro.2014.07.523

70. Pusavec F, Kopac J (2009) Achieving and implementation of sustainability principles in machining processes. Adv Prod Eng Manag 4:151-160

71. Pušavec F, Govekar E, Kopač J, Jawahir IS (2011) The influence of cryogenic cooling on process stability in turning operations. CIRP Ann Manuf Technol 60:101-104. https://doi.org/10.1016/j.cirp. 2011.03.096

72. Hong SY, Ding Y (2001) Cooling approaches and cutting temperatures in cryogenic machining of Ti-6Al-4V. Int J Mach Tools Manuf 41:1417-1437. https://doi.org/10.1016/S0890-6955(01) 00026-8 
73. Lu T, Kudaravalli R, Georgiou G (2018) Cryogenic machining through the spindle and tool for improved machining process performance and sustainability: Pt. II, sustainability performance study. Procedia Manuf 21:273-280. https://doi.org/10.1016/J. PROMFG.2018.02.121

74. Nouri M, Fussell BK, Ziniti BL, Linder E (2015) Real-time tool wear monitoring in milling using a cutting condition independent method. Int J Mach Tools Manuf 89:1-13. https://doi.org/10.1016/ j.ijmachtools.2014.10.011

75. Montgomery D (2001) Design and analysis of experiments, 5th edn. John Wiley and Sons, New York

76. Albertelli P (2017) Energy saving opportunities in direct drive machine tool spindles. J Clean Prod 165:855-873. https://doi.org/10. 1016/J.JCLEPRO.2017.07.175

77. Albertelli P, Keshari A, Matta A (2016) Energy oriented multi cutting parameter optimization in face milling. J Clean Prod:137. https://doi.org/10.1016/j.jclepro.2016.04.012

78. Borgia S, Albertelli P, Bianchi G (2017) A simulation approach for predicting energy use during general milling operations. Int J Adv
Manuf Technol 90:3187-3201. https://doi.org/10.1007/s00170016-9654-5

79. Rajemi MF, Mativenga PT, Aramcharoen A (2010) Sustainable machining: selection of optimum turning conditions based on minimum energy considerations. J Clean Prod 18:1059-1065. https:// doi.org/10.1016/j.jclepro.2010.01.025

80. ISO standard (2018) Machine tools - environmental evaluation of machine tools - part II: Methods for measuring energy supplied to machine tools and machine tool components

81. Borremans M (2019) Pumps and compressors. John Wiley \& Sons Ltd, New York

82. Supekar SD, Graziano DJ, Skerlos SJ, Cresko J (2019) LCI data for materials and processes comparing energy and water use of aqueous and gas-based metalworking fluids. https://zenodo.org/record/ 3565781\#.X8pfJNhKiMo. Accessed 13 Jan 2021

Publisher's note Springer Nature remains neutral with regard to jurisdictional claims in published maps and institutional affiliations. 